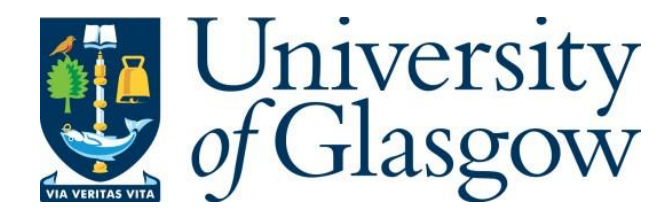

Mousavi, S. M., Kamali, R., Sotoudeh, F., Pourabidi, R., Karimi, N. and Jeung, I.S. (2019) A comprehensive investigation of acoustic power level in a moderate or intense low oxygen dilution in a jet-in-hot-coflow under various working conditions. Aerospace Science and Technology, 93, 105339.

(doi:10.1016/j.ast.2019.105339)

There may be differences between this version and the published version. You are advised to consult the publisher's version if you wish to cite from it.

http://eprints.gla.ac.uk/192788/

Deposited on: 12 August 2019

Enlighten - Research publications by members of the University of Glasgow http://eprints.gla.ac.uk 


\title{
A comprehensive investigation of acoustic power level in a moderate or intense low oxygen dilution in a jet-in-hot-coflow under various working conditions
}

\author{
Seyed Mahmood Mousavi ${ }^{1}$, Reza Kamali ${ }^{1 *}$, Freshteh Sotoudeh ${ }^{1}$, Reza Pourabidi ${ }^{1}$, Nader Karimi ${ }^{2}$, In-Seuck Jeung ${ }^{3}$ \\ ${ }^{1}$ School of Mechanical Engineering, Shiraz University, Shiraz 71348-51154, Iran \\ ${ }^{2}$ School of Engineering, University of Glasgow, Glasgow G12 8QQ, United Kingdom \\ ${ }^{3}$ Department of Aerospace Engineering, Seoul National University, Seoul, 08826, Republic of Korea
}

\begin{abstract}
Reducing the level of noise emission is an important requirement in modern propulsion and power generation. This requires gaining a deeper understanding of the underlying physics and identifying the key parameters dominating noise generation in modern combustion technologies. Thus, this paper investigates the effect of several working parameters on moderate or intense low oxygen dilution (MILD) combustion noise. A finite volume solver, GRI-Mech 2.11 with 247 reactions and 49 species, k- $\varepsilon$ RNG turbulence model as well as the EDC model are used to develop a computational model of the reactive flow, while the volume fraction and time scale constants are set to 3 and 1, respectively. After validating the numerical method by comparison with the experimental data, MILD combustion is simulated under various conditions to study the noise emission. The results show that modifying the inlet conditions such as changes in species mass fractions, inlet temperature, and inlet Reynolds number alter the acoustic power level through variations in heat release.
\end{abstract}

Keywords: MILD combustion, noise simulation, direct combustion noise.

\begin{tabular}{|lcll|}
\hline Nomenclature & & \\
\hline \multicolumn{2}{|l|}{ Symbols } & $Y_{i}^{*}$ & fine-scale species mass fraction \\
& & after reacting over the time $\tau^{*}$ \\
A pre-exponential factor & $Y_{i}$ & mass fraction of species \\
mixture fraction
\end{tabular}

\footnotetext{
*Corresponding author: rkamali@shirazu.ac.ir
} 


\begin{tabular}{|c|c|c|c|}
\hline [B] & molar concentration of substances B & \multicolumn{2}{|c|}{ Greek letters } \\
\hline$a_{0}$ & speed of sound & $\alpha$ & model constant \\
\hline$C_{\xi}$ & volume fraction constant & $\beta$ & coefficient of thermal expansion \\
\hline$C_{\tau}$ & time scale constant & $\varepsilon$ & $\begin{array}{l}\text { rate of dissipation of turbulence } \\
\text { energy }\end{array}$ \\
\hline $\mathrm{D}$ & diffusion tensor & $\mu_{\mathrm{i}}$ & eddy viscosity, Pa.s \\
\hline $\mathrm{E}_{\mathrm{a}}$ & activation energy & $\lambda$ & thermal conductivity \\
\hline $\mathrm{k}$ & turbulence kinetic energy & $v$ & kinematic viscosity, $\mathrm{m} 2 / \mathrm{s}$ \\
\hline 1 & length scales & & \\
\hline $\mathrm{m}$ & partial order in $[\mathrm{A}]$ & & \\
\hline $\mathrm{n}$ & partial order in $[\mathrm{B}]$ & $\rho$ & density, $\mathrm{kg} / \mathrm{m} 3$ \\
\hline $\mathrm{N}$ & $\begin{array}{l}\text { total number of fluid phase chemical } \\
\text { species present in the system }\end{array}$ & $\tau_{\tau}$ & stress tensor \\
\hline$P_{\text {ref }}$ & reference acoustic power & \multicolumn{2}{|c|}{ Abbreviations } \\
\hline $\mathrm{R}$ & gas constant & CFD & Computational fluid dynamics \\
\hline $\mathrm{R}_{\mathrm{i}}$ & $\begin{array}{l}\text { net rate of production of species i by } \\
\text { chemical reaction }\end{array}$ & EDC & Eddy dissipation concept \\
\hline $\mathrm{S}_{\mathrm{i}}$ & rate of creation source & FVM & Finite volume method \\
\hline $\mathrm{T}$ & temperature, $\mathrm{K}$ & $\begin{array}{l}\text { GRI- } \\
\text { Mech }\end{array}$ & Detailed reaction mechanism \\
\hline $\mathrm{u}_{\mathrm{i}}$ & $\begin{array}{l}\text { velocity component in the } \\
\text { corresponding direction }\end{array}$ & $\mathrm{JHC}$ & Jet-flame-in-hot-coflow \\
\hline$u_{t}$ & turbulence velocity & & $\begin{array}{l}\text { Moderate or intense low oxygen } \\
\text { dilution }\end{array}$ \\
\hline & & RNG & Re-Normalization Group \\
\hline
\end{tabular}

\section{1- Introduction}

Moderate or intense low-oxygen dilution (MILD) combustion is a clean and efficient energy conversion technology. MILD combustion has attracted significant interest in recent years due to its high thermal efficiency, low pollutant emissions and homogenized temperature in the combustion chamber. This technology is a promising option for practical applications and a significanat amount of research effort has been already devoted to further understand various aspects of MILD combustion. For instance, Parente et al. [1-5] conducted a series of studies on reactive flows pertinent to MILD combustion. Mousavi et al. [6-9] examined MILD (flameless oxidation) regime under various working conditions such as angled injection and reported that angled injection leads to an increase in turbulence intensity and reduces the emission of air 
pollutants. Khalil et al. [10] evaluated the flameless regime criteria based on exhaust gas recirculation and mixing using computational fluid dynamics. They found that reduction in the air jet diameter by $50 \%$ increase recirculation ratio by $100 \%$. The role of radicals on MILD combustion inception was studied by Doan and Swaminathan [11] through using direct numerical simulation (DNS) . Tian et al. [12] applied MILD condition to a co-axial-jet I-shaped recuperative radiant tube for further performance enhancement. Xie et al. [13] designed a novel burner to improve MILD combustion performance. These authors showed that injecting pure oxygen and an inert gas separately into the furnace leads to more uniform temperature distribution and lower $\mathrm{NO}_{\mathrm{x}}$ emission. Shu et al. [14] investigated $\mathrm{NO}$ formation in MILD combustion of a $\mathrm{CH}_{4}$ jet flame in hot oxidizer co-flow (JHC) diluted by $\mathrm{N}_{2}, \mathrm{H}_{2} \mathrm{O}$, and $\mathrm{CO}_{2}$, respectively. Their results showed that the mass fractions of $\mathrm{OH}, \mathrm{H}$ and $\mathrm{O}$ could be varied substantially when the diluent change from $\mathrm{N}_{2}$ to $\mathrm{H}_{2} \mathrm{O}$ or $\mathrm{CO}_{2}$.

Along with the problems of pollutant emissions and combustion efficiency, the mechanisms of noise emission in a reactive process is being studied. This is because a profound understanding of these phenomena is an essential necessity for describing the overall noise generation and emission in various applications [15]. In general, combustion noise is categorized to direct and indirect noise. Direct combustion noise is caused by unsteady heat release resulting from the interactions between chemical reactions and turbulence interactions and various instabilities of fluid dynamic, acoustic and chemical origin. Indirect combustion noise, however, is emitted by acceleration of density (entropy) waves in the exit nozzle of the combustor [16]. An excellent review of various unsteady phenomena in reactive gas systems and their relevance to sound generation is provided by Toong [17]. In recent years, many researchers have dealt with this issue [18-22]. The followings provide a brief overview of the recent studies in this area. 
Kings and Bake [23] investigated the noise emission in a nozzle caused by accelerated vorticity waves. It is found the vortex noise is related to the amount of the injected air by a quadratic dependency. Dowling and Mahmoudi [16] reviewed the experimental, theoretical and numerical investigations of combustion noise. Their work included the direct and indirect sources of combustion noise. Ullrich and Sattelmayer [24] examined the basic effects of direct and indirect combustion noise generation numerically. They evaluated the coupling behavior between acoustic, entropy and vorticity waves and the fluctuating heat release in terms of frequencydependent transfer functions. It was found that the impact of the indirect noise on the total noise increases with the mean flow acceleration and in the low-frequency regime. Jacobs and Tinney [25] developed a theoretical reactive flow model to investigate the effects of ieal gas assumption on aeroacoustics over a range of equivalence ratios. It was shown that the area ratio required for fully expanded flow is more sensitive to gas properties rather than changes in the ratio of temperature. The indirect combustion noise generation with compositional inhomogeneities examined theoretically by Magri et al. [26] who found that the compositional noise is dependent on the local mixture composition and can exceed entropy noise for fuel-lean conditions and supercritical nozzle flows. The choked laboratory scale combustor noise emission mechanisms were studied by Kings et al. [27] experimentally and numerically. They evaluated the acoustic and entropy fluctuations at the combustion chamber outlet for different operation conditions to estimate the direct and indirect combustion noise contributions. Ferand et al. [28] described the methodology combining CFD methods and analytical models used for the prevision of combustion noise. They showed that their results in terms of spectral repartition and acoustic level. Langella et al. [29] numerically predicted the noise emission of a low Mach number premixed combustion in an open environment. They computed the level of far field sound 
pressure and its power spectral density for various equivalence ratios and turbulence levels. O'Brien et al. [30] studied noise generation in a dual swirl combustion chamber with a converging-diverging nozzle. They represented a test case for probing the physics behind both direct and indirect combustion noise. The combustion noise of turbulent flames is investigated by Ullrich et al. [31] using linearized Navier-Stokes equations and large eddy simulation methodology. The results revealed that the noise emission of combustion process is mainly related to the heat release spectrum rather than by the aerodynamic combustor flow field. Lackhove et al. [32] presented a numerical approach which exploits the different scales prevalent in combustion systems by computing the flow field and acoustics separately and coupling both simulations in real time. They showed that the presented methodology requires up to 10 times less computational effort while being able to deliver results significantly faster than a compressible LES. Ihme et al. [33] examined relative contributions of different noise source mechanisms and the model fidelity necessary to accurately describe their relevant physical processes. They performed idealized one-dimensional compact and non-compact nozzleanalysis. The results showed that the non-compact nozzle theory is necessary to accurately capture phase-cancellation effects between entropy and composition noise, and the linearized Euler formulation is required to account for complex mode shapes of the perturbations exiting the combustor and entering the downstream nozzle. The entropy dispersion effects on the combustion noise level of a combustor and turbine outlet were studied by Mahmoudi et al [34] and Fattahi and co-workers [35-37]. They reported that entropy dispersion is an important factor to increase the level of noise emission in turbines and nozzles. Tam et al. [38] investigated the physical processes at the generation of combustion noise including entropy wave, acoustic wave, and vorticity wave. In their numerical and theoretical works, Fattahi et al. [39] investigated the 
dispersion of entropy wave during its conversion in gas turbine combustors. In addition, many researchers have investigated the effects of various parameters on the level of noise emission in different combustion process. For example, Merk et al. [40] investigated the effects of velocity fluctuations of a turbulent premixed flame. Pillai and Kurose [41] analyzed the characteristics of noise radiation in a turbulent spray flame. Grimm et al. [42] investigated the impact of global equivalence ratio and thermal power variation on broadband combustion noise emission in a swirl-stabilized burner experimentally and numerically.

The preceding review of literature shows that some aspects of MILD combustion have been already investigated in-depth. However, there is a lack of study to clarify the level of noise generation by this technology. To fill this gas, MILD combustion in a JHC is investigated, using the eddy dissipation concept (EDC) model, k- $\varepsilon$ RNG turbulence model and GRI 2.11 reaction mechanism [43]. After ensuring the accuracy of the developed finite volume method (FVM) by comparing the obtained results with the existing experimental data [44], the acoustic power level of MILD combustion is analyzed under several conditions using broadband noise source models.

\section{2- Governing Equations}

The compressible form of governing equations for a reactive flow including the conservation of mass, momentum, energy and a transport equation for the species mass fractions can be written as follows:

$$
\begin{gathered}
\frac{\partial \rho}{\partial t}+\nabla \cdot(\rho u)=0 \\
\frac{\partial(\rho u)}{\partial t}+\nabla \cdot(\rho u u)+\nabla p=\nabla \cdot \tau \\
\frac{\partial(\rho h)}{\partial t}+\nabla \cdot(\rho u h)-\frac{\partial p}{\partial t}-u \cdot \nabla p=\nabla \cdot(\lambda \nabla T)+\tau_{\tau}: \nabla u
\end{gathered}
$$




$$
\frac{\partial\left(\rho Y_{i}\right)}{\partial t}+\nabla \cdot\left(\rho u Y_{i}\right)=\nabla \cdot\left(D \nabla Y_{i}\right)+S_{i}
$$

In the above equations, $i=1,2, \ldots, N_{s}-1$ is the number of species. The component $\nabla \cdot(\rho u u)$ in Eq. 2 is defined as resulting in a column vector after application of the differential operator to the dyadic product $\rho u u$. Also, the same applies to the handling of the tensor of tensions $\nabla \tau_{\tau}$ in Eq. 2 . The stress tensor for a variable density flow is defined as:

$$
\tau_{\tau}=2 \mu\left[\boldsymbol{S}-\frac{1}{3}(\nabla \cdot u) \boldsymbol{I}\right]
$$

where

$$
S=\frac{1}{2}\left(\nabla u+(\nabla u)^{T}\right)
$$

The equation of state relates the pressure $(p)$ to temperature $(T)$ and density $(\rho)$, while the specific gas constant $R$ can be defined in terms of the component mass fractions $Y_{\alpha}$ and molar masses $M_{\alpha}$.

$$
\rho=\frac{p_{r e f}+p}{R T}
$$

The above equations describe compressible reactive flow. However, in this work, incompressible CFD simulations are conducted [45]. This implies some simplifications such as gas density not being a function of the pressure and neglecting the effect of hydrodynamic pressure fluctuations on energy. Moreover, the enthalpy is defined as:

$$
h=\int_{T_{0}}^{T} c_{p} d T+\sum_{\alpha=1}^{N_{s}} \Delta h_{f, \alpha}^{0} Y_{\alpha}
$$

where $\Delta h_{f, \alpha}^{0}$ represents the standard enthalpy of formation at reference conditions for species $\alpha$ and $c_{p}$ is the heat capacity.

\section{3- Turbulence Model}


In the present work, the k- $\varepsilon$ RNG method is used to renormalize equations of Navier-Stokes to account for the effects of smaller scales of motion [46]. Its application results in a modified form of the $\varepsilon$-equation which accounts for the different scales of motion through changes in the production term. The transport equations for $k$ and $\varepsilon$ can be written at different forms; a simple interpretation by neglecting the buoyancy force is:

$$
\begin{gathered}
\frac{\partial}{\partial t}(\rho k)+\frac{\partial}{\partial x_{i}}\left(\rho k u_{i}\right)=\frac{\partial}{\partial x_{j}}\left[\left(\mu+\frac{\mu_{t}}{\sigma_{k}}\right) \frac{\partial k}{\partial x_{j}}\right]+P_{k}-\rho \varepsilon \\
\frac{\partial}{\partial t}(\rho \varepsilon)+\frac{\partial}{\partial x_{i}}\left(\rho \varepsilon u_{i}\right)=\frac{\partial}{\partial x_{j}}\left[\left(\mu+\frac{\mu_{t}}{\sigma_{\varepsilon}}\right) \frac{\partial \varepsilon}{\partial x_{j}}\right]+C_{1 \varepsilon} \frac{\varepsilon}{k} P_{k}-C_{2 \varepsilon}^{*} \rho \frac{\varepsilon^{2}}{k}
\end{gathered}
$$

in which

$$
\begin{gathered}
\mu_{t}=\rho C_{\mu} \frac{k^{2}}{\varepsilon} \\
P_{k}=\mu_{t} \sqrt{2 S_{i j} S_{i j}} \\
C_{2 \varepsilon}^{*}=C_{2 \varepsilon}+\frac{C_{\mu} \eta^{3}\left(1-\eta / \eta_{0}\right)}{1+\beta \eta^{3}}
\end{gathered}
$$

and

$$
\begin{aligned}
& \eta=\frac{\left(2 S_{i j} S_{i j}\right)^{1 / 2} k}{\varepsilon} \\
& \beta=-\frac{1}{\rho}\left(\frac{\partial \rho}{\partial T}\right)_{p}
\end{aligned}
$$

Furthermore, the constants in the above equations are as follows:

$\eta_{0}=0.438, \beta=0.012, \mathrm{C}_{\varepsilon 2}=1.68, \mathrm{C}_{\varepsilon 1}=1.42, \sigma_{\varepsilon}=0.7194, \sigma_{k}=0.7194, \mathrm{C}_{\mu}=0.0845$

\section{4- Broadband Noise Source Models}


Generally, noise and acoustic energy do not have any distinct tones in turbulent flows, and they are continuously spread over a broad range of frequencies. To predict the noise sources, the broadband noise [47-50] computable from RANS equations can be utilized. This model is in connection with semi-empirical correlations and Lighthill's acoustic analogy [51]. Proudman [52], derived an equation for the power of acoustic which generated by isotropic turbulence without mean flow using Lighthill's acoustic analogy and neglecting the retarded time difference. Then, Lilley [53] re-derived the derivation of Proudman [52]. These two derivations yield acoustic power due to the unit volume of isotropic turbulence as follows:

$$
P_{A}=\alpha_{\varepsilon} \rho_{0}\left(\frac{u_{t}^{3}}{l}\right) \frac{u_{t}^{5}}{a_{0}^{5}}
$$

In terms of $k$ and $\varepsilon$, Eq. 16 can be rewritten as:

$$
P_{A}=\alpha_{\varepsilon} \rho_{0} \varepsilon M_{t}^{5}
$$

with

$$
M_{t}=\frac{\sqrt{2 k}}{a_{0}}
$$

in the present finite volume code, the rescaled constant $\alpha_{\varepsilon}$ is set to 0.1 on the basis of the calibration of Sarkar and Hussaini [54]. Finally, the acoustic power can be computed as follows:

$$
L_{p}=10 \log \left(\frac{P_{A}}{\mathrm{P}_{\mathrm{ref}}}\right)
$$

\section{5- Eddy Dissipation Concept (EDC)}

In the present finite volume code, the conservation equations for chemical species are solved by calculating the local mass fraction of each species, $Y_{i}$, from the convection-diffusion equation for 
the $i^{\text {th }}$ species. The general form of conservation equations for chemical species, which solved for $\mathrm{N}-\mathrm{q}$ species, are as follows:

$$
\frac{\partial}{\partial t}\left(\rho Y_{i}\right)=\nabla \cdot\left(\rho \stackrel{\mathrm{r}}{\nu} Y_{i}\right)=-\nabla \cdot \stackrel{\mathrm{r}}{J_{i}}+R_{i}+S_{i}
$$

in which, the $\mathrm{N}^{\text {th }}$ mass fraction is the negative sum of the $\mathrm{N}-1$ solved mass fractions. To reduce the numerical error, the $\mathrm{N}^{\text {th }}$ species is selected as the species with the overall largest mass fraction [55]. The EDC model is a concept to treat the turbulence and chemistry in flames [56, 57]. This model is based on this assumption that the reactions occur in the fine scales which is a small turbulent structure by the length fraction of

$$
\xi^{*}=C_{\xi}\left(\frac{v \varepsilon}{k^{2}}\right)^{1 / 4}
$$

The volume fraction of the fine scales is calculated as $\xi^{* 3}$. Furthermore, the time scale of the species is as follows:

$$
\tau^{*}=C_{\tau}\left(\frac{v}{\varepsilon}\right)^{1 / 2}
$$

In this work, the volume fraction constant $\left(C_{\xi}\right)$ and time scale constant $\left(C_{\tau}\right)$ are set to 3 and 1 , respectively. In addition, the source term $R_{i}$ for the mean species $i$ in the conservation equation shown in Eq. 20 is:

$$
R_{i}=\frac{\rho\left(\xi^{*}\right)^{2}}{\tau^{*}\left[1-\left(\xi^{*}\right)^{3}\right]}\left(Y_{i}^{*}-Y_{i}\right)
$$

In the above equation, the superscript ${ }^{*}$ denotes the fine-scale quantities. The detailed chemical mechanisms can be incorporated into turbulent reactive flows by the EDC model. Also, GRI. 2.11 reaction mechanism is used. In this mechanism, the reaction rate is calculated by 


$$
r=A e^{-E_{a} / R T}[A]^{m}[B]^{n}
$$

where $A, E_{a}, R, m, n,[A]$ and $[B]$ are the pre-exponential factor, activation energy, gas constant, the molar concentrations of substances. Furthermore, in order to study the flame structure in the JHC, the mixture fraction $Z$ is suggested by [44] which is widely adopted to inspect nonpremixed combustion. It is due to this fact that the results are independent of the JHC structure. The mixture fraction is related to the mass balance of $C, H$ and $O$ elements and it can be calculated as follows [58]:

$$
Z=\frac{\frac{2\left(Y_{C}-Y_{C, 2}\right)}{W_{C}}+\frac{2\left(Y_{H}-Y_{H, 2}\right)}{2 W_{H}}-\frac{2\left(Y_{O}-Y_{O, 2}\right)}{W_{O}}}{\frac{2\left(Y_{C, 1}-Y_{C, 2}\right)}{W_{C}}+\frac{2\left(Y_{H, 1}-Y_{H, 2}\right)}{2 W_{H}}-\frac{2\left(Y_{O, 1}-Y_{O, 2}\right)}{W_{O}}}
$$

where $Y_{j}$ and $W_{j}$ are the mass fraction and atomic mass for element $j$, respectively and the value extracted from either the fuel or the oxidant is showed by subscripts 1 and 2 . Using this criterion, the mixture fraction would be 1 and 0 in the fuel and oxidant streams, respectively.

\section{6- Geometry and Boundary Conditions}

Fig. 1 shows the computational domain of the current study. As shown in Fig. 1, this JHC which is known as Dally burner is comprised of three inlets and one outlet. The outlet radius is equal to $210 \mathrm{~mm}$ and placed at the end of the JHC. Also, the inlets include a fuel inlet at the center of the JHC by $4.25 \mathrm{~mm}$ diameter, an $82 \mathrm{~mm}$ diameter hot co-flow inlet around the fuel inlet as well as a wind tunnel by $420 \mathrm{~mm}$ diameter, which is placed around the hot co-flow inlet. In addition, the JHC's length is $500 \mathrm{~mm}$. This numerical investigation is conducted in an axisymmetric computational domain and a mesh with 45000 cells is used after studying the grid sensitivity.

Table 1 shows the inlet conditions for different cases at the present study and the inlet velocities, inlet temperatures and the mass fractions are clearly specified. According to this table, for the 
cases $(\mathrm{HM})$ of 1 to 6 the amounts of $\mathrm{O}_{2}$ and $\mathrm{N}_{2}$ are changed and the variable parameter for the cases HM1 and HM7-9 is the inlet temperature. In addition, the inlet fuel ratio is changed for the HM9 to HM12 and at the end, HM9 and HM10-12 represent the variations of inlet hot co-flow Reynolds number.

\section{7- Results and Discussions}

\subsection{Validation}

In this section, the results from the finite volume code are compared with the experimental data [44] to validate the numerical framework. To achieve this, a comparison between the predicted mixture fraction and the experimental data [44] at three radial distances of $30,60,120 \mathrm{~mm}$ is shown in Fig. 2. As depicted by Fig. 2, there is a reasonable agreement between the mixture fractions (for HM1) at all positions and temperature (for HM3) obtained from the current finite volume code and those obtained experimentally; showing that the present numerical method is capable of predicting the MILD combustion behavior at various working conditions.

\subsection{Effects of inlet $\mathrm{O}_{2}$ mass fraction}

In this section, the dependency of noise emissions in MILD condition on the inlet hot co-flow mass fraction of $\mathrm{O}_{2}$ (HM1 to HM6) is investigated. As the mass fraction of $\mathrm{O}_{2}$ increases and the mass fraction of $\mathrm{N}_{2}$ decreases, the heat capacity of reactive flow decreases. Therefore, based on Fig. 3, the flow temperature increases. Temperature has an important role in the reaction rate and zone. The free radical of $\mathrm{OH}$ shows the reaction zone of the combustion process and it can be seen from Fig. 4 that increasing in the inlet mass fraction of $\mathrm{O}_{2}$ leads to a reduction in the thickness of the $\mathrm{OH}$ distribution region but the local concentration of this radical increases. Furthermore, it is evident from Figs. 4 and 5 that the starting point of reaction zone approaches the inlet nozzle with increasing the mass fraction of $\mathrm{O}_{2}$. In addition, Fig. 6a-b demonstrates that 
the maximum amount of $\mathrm{OH}$ mass fraction increases with the enhancement of the inlet mass fraction of $\mathrm{O}_{2}$. This implies that the reaction zone has been strengthened and that the maximum rate of reaction increases (Fig.7). Besides, as is clear from Fig 6a, the amount of HCO radical increases, which means that the heat release of the combustion process increases. Moreover, the amount of $\mathrm{CH}_{2} \mathrm{O}$ and $\mathrm{HO}_{2}$, as indicators of heat release and activation of chemical kinetics, respectively, rise with the enhancement of inlet $\mathrm{O}_{2}$ concentration. Consequently, the increased heat release, as a direct source of noise emission in the combustion process, causes the level of acoustic power to increase according to Fig. 7.

\subsection{Effects of fuel temperature variations}

In this section the effects of inlet fuel temperature variations on the noise emission is investigated. To this end, HM1, HM7 and HM9 conditions in Table 1 are considered. Figure 8 shows the contour of $\mathrm{OH}$ mass fraction for different inlet fuel temperatures, such as 300,350 , 400 , and $450 \mathrm{~K}$. The increase in fuel temperature prepares the mixture for reaction in a shorter time. Therefore, according to Figs. 8 and 9, the starting point of the reaction zone moves toward the inlet nozzle slightly by increasing the inlet fuel temperature. However, given Fig. 9, it is evident that increasing the inlet fuel temperature leads to the reduction of mole fraction of $\mathrm{OH}$ and HCO. These two radical types show the heat release of combustion process. A decrease in the amount of $\mathrm{OH}$ and $\mathrm{HCO}$ radical reduces the net reaction rate in the reaction zone, which is clear from Fig. 9. As mentioned above, the fluctuation in heat release of combustion process is a direct source of noise emission. Consequently, by increasing the inlet fuel temperature, the acoustic power level is reduced as shown in Fig. 10. In addition, the level of acoustic power distribution and turbulence intensity for various inlet fuel temperatures are depicted in Fig. 10. From the observations, the acoustic power level is reduced by increasing the fuel temperature 
except at the inlet region, which has a high temperature. The turbulence intensity is another source of noise emission. This parameter is dependent on the quality of the combustion directly. This means that the reduction of turbulence intensity will reduce combustion quality. Fig. 10 demonstrates that an increase in the inlet fuel temperature reduces the turbulence intensity in the reaction zone. Therefore, the combustion process moves away from being complete; consequently, the maximum temperature of the process is reduced, and the level of acoustic power diminishes.

\subsection{Effects of $\mathrm{H}_{2}$ variations}

In this section, the effect of $\mathrm{H}_{2}$ to $\mathrm{CH}_{4}$ ratio on the level of acoustic power of MILD combustion are investigated for the conditions of Table 1 and for cases HM9 to HM12. Figure 11(a-b) shows the temperature and $\mathrm{OH}$ free radical dependency on adding $\mathrm{H}_{2}$ species as a fuel with high flammability. Evidently, adding $\mathrm{H}_{2}$ mass fraction leads to the reduction of temperature along the JHC. It should be mentioned that by getting away from the flow inlet and approaching the JHC outlet, the temperature differences between various cases are affected by changing the amount of $\mathrm{H}_{2}$ inlet mass fraction; consequently, the power acoustic level has a considerable difference at the outlet of the JHC. Furthermore, Fig. 12 demonstrates the $\mathrm{OH}$ free radical distribution for various fuel inlet components. It is shown that as the mass fraction of $\mathrm{H}_{2}$ increases, the starting point of reaction zone moves toward the inlet nozzle (Fig. 13). This is due to the increase in flammability of the fuel-air mixture. This helps the mixture to have more opportunity to react and causes the temperature to decrease throughout the JHC. In addition, Fig. 11b indicates the variation of $\mathrm{OH}$ free radical mass fraction by changing the amount of $\mathrm{H}_{2}$ inlet mass fraction. As seen, by increasing the $\mathrm{H}_{2}$ to $\mathrm{CH}_{4}$ ratio, the amount of $\mathrm{OH}$ free radical is decreased, which results 
in reduction of released heat in the JHC. Hence, as shown in Fig. 14, the acoustic power at the outlet of JHC decreases.

\subsection{Reynolds number effects}

In this section, the effect of the inlet hot co-flow Reynolds number on level of acoustic power of MILD combustion is investigated. The simulation results for Reynolds numbers of 5000, 7500, 10000 and 15000 (HM9 and HM13-15 in Table 1) are compared in Fig. 15, which represents the maximum level of acoustic power, turbulence intensity, net reaction rate, and the starting point of reaction zone in JHC burner. Increasing the Reynolds number causes the residence time of reacting flow to decrease and intensifies the instability of the flame. In addition, in terms of turbulence intensity, as the main factor in mixing process of fuel and oxidizer, a decreasing trend is observed in Fig. 15 by increasing the Reynolds number. Therefore, the combustible flow has a lower opportunity to go through a complete reaction process. Consequently, the combustion temperature is reduced and as shown in Fig. 15, the net reaction rate is decreased, and the starting point of reaction zones moves far from the inlet nozzle. A reduction in net reaction rate reduces the amount of heat release as a direct source of noise emission from combustion process. Finally, the level of acoustic power of MILD combustion is reduced by increasing the inlet Reynolds number.

\section{Conclusion}

In this study, the effects of several conditions on the acoustic power level of MILD combustion were investigated using a finite volume code. GRI-Mech 2.11 with 247 reactions and 49 species, k- $\varepsilon$ RNG turbulence model, as well as the EDC model with the volume fraction constant and time scale constant which set to 3 and 1, respectively, were used. The obtained results for some parameters were compared with experimental data [44] which resulted in good agreement 
between them. After that, the level of acoustic power of MILD combustion was investigated under the conditions of the changes in species mass fractions, inlet temperature, and inlet Reynolds number. The key findings are as follows:

- Increasing in the inlet mass fraction of $\mathrm{O}_{2}$ leads to a reduction in the thickness of $\mathrm{OH}$ distribution region and moves the starting point of reaction zone toward the inlet nozzle. This increases the maximum amount of $\mathrm{OH}$ and $\mathrm{HCO}$ mass fractions and rate of reaction and following them it increases the heat release of the combustion process. As a result, increases in $\mathrm{O}_{2}$ mass fraction enhances the direct source of noise emission in the combustion process and causes the level of acoustic power to grow.

- The increase in fuel temperature prepares the mixture for reaction in a shorter time. Therefore, the starting point of the reaction zone moves toward the inlet nozzle slightly, and $\mathrm{OH}$ and $\mathrm{HCO}$ free radicals are reduced by increasing the inlet fuel temperature. Furthermore, the results show that an increase in the inlet fuel temperature reduces the turbulence intensity in the reaction zone following a reduction of the maximum temperature of MILD combustion. Consequently, the acoustic power level decreases.

- Adding $\mathrm{H}_{2}$ mass fraction leads to the reduction of temperature and $\mathrm{OH}$ free radical and the starting point of reaction zone moves toward the inlet nozzle. Hence, the acoustic power at the outlet of JHC decreases.

- By increasing Reynolds number, turbulence intensity, combustion temperature and net reaction rate are reduced, and starting point of the reaction zones moves far from the inlet nozzle. Finally, the amount of heat release as a direct source of noise emission and following it the level of acoustic power of MILD combustion are decreased by increasing the inlet Reynolds number. 


\section{References}

[1] M. Ferrarotti, M. Fürst, E. Cresci, W. de Paepe, A. Parente, Key Modeling Aspects in the Simulation of a Quasi-industrial $20 \mathrm{~kW}$ Moderate or Intense Low-oxygen Dilution Combustion Chamber, Energy \& Fuels, 32 (2018) 10228-10241.

[2] V. Fortunato, A. Giraldo, M. Rouabah, R. Nacereddine, M. Delanaye, A. Parente, Experimental and Numerical Investigation of a MILD Combustion Chamber for Micro Gas Turbine Applications, Energies, 11 (2018) 3363.

[3] G. Bagheri, M.L. Lavadera, E. Ranzi, M. Pelucchi, P. Sabia, M. de Joannon, A. Parente, T. Faravelli, Thermochemical oscillation of methane MILD combustion diluted with N2/CO2/H2O, Combustion Science and Technology, 191 (2019) 68-80.

[4] R. Longo, M. Fürst, A. Bellemans, M. Ferrarotti, M. Derudi, A. Parente, CFD dispersion study based on a variable Schmidt formulation for flows around different configurations of ground-mounted buildings, Building and Environment, 154 (2019) 336-347.

[5] A. Bertolino, A. Stagni, A. Cuoci, T. Faravelli, A. Parente, A. Frassoldati, Prediction of flammable range for pure fuels and mixtures using detailed kinetics, Combustion and Flame, 207 (2019) 120-133.

[6] S.M. Mousavi, J. Abolfazli Esfahani, D. Jafari, The effect of adding H2 to the Flameless Oxidation (FLOX) of biogas on pollutants emission, 2nd Annual Clean Energy Conference (ACEC), International Center for Advanced Science and Technology and Environmental Sciences, Cilivica, Kerman, Iran, 2012.

[7] S.M. Mousavi, J. Abolfazli-Esfahani, Numerical Investigation of the Flameless Oxidation of Natural Gas in the IFRF Furnace Using Large Eddy Simulation, International Journal of Spray and Combustion Dynamics, 6 (2014) 387-410.

[8] S.M. Mousavi, J. Abolfazli Esfahani, M. YazdiMamaghani, Numerical Study of Entropy Generation in the Flameless Oxidation Using Large Eddy Simulation Model and OpenFOAM Software, International Journal of Thermodynamics 17 (2014) 202-208.

[9] R. Kamali, S.M. Mousavi, A.R. Binesh, J. Abolfazli-Esfahani, Large eddy simulation of the flameless oxidation in the IFRF furnace with varying inlet conditions, International Journal of Spray and Combustion Dynamics, 9 (2016) 102-115.

[10] H.M. Khalil, Y.A. Eldrainy, K.M. Saqr, W.A. Abdelghaffar, Evaluation criteria for a flameless combustor based on recirculation and mixing - A CFD approach, Acta Astronautica, 152 (2018) 127-136.

[11] N.A.K. Doan, N. Swaminathan, Role of radicals on MILD combustion inception, Proceedings of the Combustion Institute, 37 (2019) 4539-4546.

[12] Y. Tian, X. Zhou, X. Ji, J. Bai, L. Yuan, Applying moderate or intense low-oxygen dilution combustion to a co-axial-jet I-shaped recuperative radiant tube for further performance enhancement, Energy, 171 (2019) 149-160.

[13] Y. Xie, Y. Tu, H. Jin, C. Luan, Z. Wang, H. Liu, Numerical study on a novel burner designed to improve MILD combustion behaviors at the oxygen enriched condition, Applied Thermal Engineering, 152 (2019) 686-696.

[14] Z. Shu, C. Dai, P. Li, J. Mi, Nitric oxide of MILD combustion of a methane jet flame in hot oxidizer coflow: Its formations and emissions under $\mathrm{H} 2 \mathrm{O}, \mathrm{CO} 2$ and $\mathrm{N} 2$ dilutions, Fuel, 234 (2018) 567-580.

[15] H.H. Chiu, M. Summerfield, Theory of combustion noise, Acta Astronautica, 1 (1974) 967984. 
[16] A.P. Dowling, Y. Mahmoudi, Combustion noise, Proceedings of the Combustion Institute, 35 (2015) 65-100.

[17] T.-Y. Toong, Instabilities in reacting flows, Acta Astronautica, 1 (1974) 317-344.

[18] Z. Sun, W. Zou, X. Zheng, Instability detection of centrifugal compressors by means of acoustic measurements, Aerospace Science and Technology, 82-83 (2018) 628-635.

[19] A. Broatch, J. García-Tíscar, F. Roig, S. Sharma, Dynamic mode decomposition of the acoustic field in radial compressors, Aerospace Science and Technology, 90 (2019) 388-400.

[20] H. Zan, W. Zhou, X. Xiao, L. Lin, J. Zhang, H. Li, Recurrence network analysis for uncovering dynamic transition of thermo-acoustic instability of supercritical hydrocarbon fuel flow, Aerospace Science and Technology, 85 (2019) 1-12.

[21] A. Ericsson, R. Rumpler, D. Sjöberg, P. Göransson, N. Wellander, J. Johansson, A combined electromagnetic and acoustic analysis of a triaxial carbon fiber weave for reflector antenna applications, Aerospace Science and Technology, 58 (2016) 401-417.

[22] A. Filippone, M. Zhang, N. Bojdo, Validation of an integrated simulation model for aircraft noise and engine emissions, Aerospace Science and Technology, 89 (2019) 370-381.

[23] N. Kings, F. Bake, Indirect combustion noise: noise generation by accelerated vorticity in a nozzle flow, International Journal of spray and combustion dynamics, 2 (2010) 253-266.

[24] W.C. Ullrich, T. Sattelmayer, Transfer functions of acoustic, entropy and vorticity waves in an annular model combustor and nozzle for the prediction of the ratio between indirect and direct combustion noise, 21st AIAA/CEAS Aeroacoustics Conference, 2015, pp. 2972.

[25] J. Jacobs, C. Tinney, A combustion model for studying the effects of ideal gas properties on jet noise, APS Division of Fluid Dynamics Meeting Abstracts, 2016.

[26] L. Magri, J. O’Brien, M. Ihme, Compositional inhomogeneities as a source of indirect combustion noise, Journal of Fluid Mechanics, 799 (2016).

[27] N. Kings, W. Tao, P. Scouflaire, F. Richecoeur, S. Ducruix, Experimental and numerical investigation of direct and indirect combustion noise contributions in a lean premixed laboratory swirled combustor, ASME Turbo Expo 2016: Turbomachinery Technical Conference and Exposition, American Society of Mechanical Engineers, 2016, pp. V04BT04A047V004BT004A047.

[28] M. Férand, T. Livebardon, S. Moreau, T. Poinsot, C. Sensiau, Numerical investigation of combustion noise from aeronautical combustor to far-field, 22nd AIAA/CEAS Aeroacoustics Conference, 2016, pp. 2747.

[29] I. Langella, Y. Mahmoudi-Larimi, N. Swaminathan, A. Dowling, Combustion noise analysis of open flames using incompressible LES, 22nd AIAA/CEAS Aeroacoustics Conference, 2016, pp. 2827.

[30] J. O'Brien, F. Bake, M. Ihme, Combustion noise simulation in a model gas-turbine combustor, Proceedings of the Summer Program, 2016, pp. 153.

[31] W.C. Ullrich, C. Hirsch, T. Sattelmayer, K. Lackhove, A. Sadiki, A. Fischer, M. Staufer, Combustion Noise Prediction Using Linearized Navier-Stokes Equations and Large-Eddy Simulation Sources, Journal of Propulsion and Power, 34 (2017) 198-212.

[32] K. Lackhove, A. Sadiki, J. Janicka, Efficient Three Dimensional Time-Domain Combustion Noise Simulation of a Premixed Flame Using Acoustic Perturbation Equations and Incompressible LES, ASME Turbo Expo 2017: Turbomachinery Technical Conference and Exposition, American Society of Mechanical Engineers, 2017, pp. V02CT43A001V002CT043A001. 
[33] M. Ihme, J. O'Brien, J. Kim, Compositional inhomogeneities as a source of indirect combustion noise: Physical mechanisms and fuel effects, 24th International Congress on Sound and Vibration, ICSV 2017, 2017.

[34] Y. Mahmoudi, A. Giusti, E. Mastorakos, A.P. Dowling, Low-Order Modeling of Combustion Noise in an Aero-Engine: The Effect of Entropy Dispersion, Journal of Engineering for Gas Turbines and Power, 140 (2018) 011502.

[35] A. Fattahi, S.M. Hosseinalipour, N. Karimi, Z. Saboohi, F. Ommi, On the response of a lean-premixed hydrogen combustor to acoustic and dissipative-dispersive entropy waves, Energy, 180 (2019) 272-291.

[36] S.M. Hosseinalipour, A. Fattahi, H. Afshari, N. Karimi, On the effects of convecting entropy waves on the combustor hydrodynamics, Applied Thermal Engineering, 110 (2017) 901909.

[37] S.M. Hosseinalipour, A. Fattahi, N. Karimi, Investigation of the transmitted noise of a combustor exit nozzle caused by burned hydrogen-hydrocarbon gases, International Journal of Hydrogen Energy, 41 (2016) 2075-2086.

[38] C.K. Tam, S.A. Parrish, The physical processes of indirect combustion noise generation, International Journal of Aeroacoustics, 17 (2018) 22-35.

[39] A. Fattahi, S.M. Hosseinalipour, N. Karimi, On the dissipation and dispersion of entropy waves in heat transferring channel flows, Physics of Fluids, 29 (2017) 087104.

[40] M. Merk, R. Gaudron, C. Silva, M. Gatti, C. Mirat, T. Schuller, W. Polifke, Prediction of combustion noise of an enclosed flame by simultaneous identification of noise source and flame dynamics, Proceedings of the Combustion Institute, 37 (2019) 5263-5270.

[41] A.L. Pillai, R. Kurose, Combustion noise analysis of a turbulent spray flame using a hybrid DNS/APE-RF approach, Combustion and Flame, 200 (2019) 168-191.

[42] F. Grimm, F. Setzwein, S. Werner, M. Stöhr, J. Dierke, R. Ewert, B. Noll, M. Aigner, Combustion Noise Dependency on Thermal Load and Global Equivalence Ratio in a SwirlStabilized Combustor, AIAA Scitech 2019 Forum, 2019, pp. 1582.

[43] C.T. Bowman, U. Stanford, I. Gas Research, GRI-Mech 2.11, an optimized detailed chemical reaction mechanism for methane combustion and no formation and reburning : topical report (February 1, 1997), Gas Research Institute, Chicago, Ill., 1997.

[44] B.B. Dally, A.N. Karpetis, R.S. Barlow, Structure of turbulent non-premixed jet flames in a diluted hot coflow, Proceedings of the Combustion Institute, 29 (2002) 1147-1154.

[45] F. Grimm, D. Ohno, S. Werner, M. Stöhr, R. Ewert, J. Dierke, B. Noll, M. Aigner, Direct Combustion Noise Simulation of a Lean Premixed Swirl Flame using Stochastic Sound Sources, 54th AIAA Aerospace Sciences Meeting, American Institute of Aeronautics and Astronautics2016.

[46] V. Yakhot, S.A. Orszag, S. Thangam, T.B. Gatski, C.G. Speziale, Development of turbulence models for shear flows by a double expansion technique, Physics of Fluids A: Fluid Dynamics, 4 (1992) 1510-1520.

[47] K. Wiesenfeld, Noisy precursors of nonlinear instabilities, Journal of Statistical Physics, 38 (1985) 1071-1097.

[48] Y. Li, M. Smith, X. Zhang, Measurement and control of aircraft landing gear broadband noise, Aerospace Science and Technology, 23 (2012) 213-223.

[49] H.H. Brouwer, On the effect of nonlinear propagation on perceived jet noise levels, Aerospace Science and Technology, 12 (2008) 74-79. 
[50] W. Dobrzynski, R. Ewert, M. Pott-Pollenske, M. Herr, J. Delfs, Research at DLR towards airframe noise prediction and reduction, Aerospace Science and Technology, 12 (2008) 80-90.

[51] H. Hassan, Scaling of combustion-generated noise, Journal of Fluid Mechanics, 66 (1974) 445-453.

[52] I. Proudman, I. Taylor Geoffrey, The generation of noise by isotropic turbulence, Proceedings of the Royal Society of London. Series A. Mathematical and Physical Sciences, 214 (1952) 119-132.

[53] G.M. Lilley, The radiated noise from isotropic turbulence, Theoretical and Computational Fluid Dynamics, 6 (1994) 281-301.

[54] S. Sarkar, M.Y. Hussaini, COMPUTATION OF THE SOUND GENERATED BY ISOTROPIC TURBULENCE, Institute for Computer Applications in Science and Engineering (ICASE), 1993.

[55] G.H. Yeoh, K.K. Yuen, Computational Fluid Dynamics in Fire Engineering : Theory, Modelling and Practice, Butterworth-Heinemann, Boston, Mass., 2010.

[56] B. Magnussen, On the structure of turbulence and a generalized eddy dissipation concept for chemical reaction in turbulent flow, 19th Aerospace Sciences Meeting, American Institute of Aeronautics and Astronautics1981.

[57] B.F. Magnussen, The Eddy Dissipation Concept-A Bridge Between Science and Technology, ECCOMAS thematic conference on computational combustion, 2005, pp. 21-24. [58] R.W. Bilger, S.H. Stårner, R.J. Kee, On reduced mechanisms for methane $\square$ air combustion in nonpremixed flames, Combustion and Flame, 80 (1990) 135-149. 


\section{List of figures}

Fig. 1 Schematic of present computational domain

Fig. 2 Validation of the current numerical method

Fig. 3 Contours of temperature for various inlet mass fraction of $\mathrm{O}_{2}$

Fig. $4 \quad \mathrm{OH}$ mass fraction for various inlet mass fractions of $\mathrm{O}_{2}$

Fig. 5 Effects of inlet mass fraction $\mathrm{O}_{2}$ on starting point of reaction zone

Fig. 6 Effects of inlet mass fraction of $\mathrm{O}_{2}$ on mass fractions of a- $\mathrm{OH}, \mathrm{HCO}$ and $\mathrm{b}-\mathrm{HO}_{2}$, $\mathrm{CH}_{2} \mathrm{O}$.

Fig. 7 Effects of inlet mass fraction of $\mathrm{O}_{2}$ on acoustic power level and net reaction rate

Fig. 8 Contour of $\mathrm{OH}$ mass fraction in various inlet fuel temperatures

Fig. 9 Effects of inlet fuel temperature on starting point of reaction zone, mole fraction of $\mathrm{HCO}, \mathrm{OH}$, and net reaction rate

Fig. 10 Effects of inlet fuel temperature on acoustic power level and turbulence intensity

Fig. 11 Effects of the inlet fuel ratio on a- temperature and b- mass fraction of $\mathrm{OH}$

Fig. $12 \mathrm{OH}$ mass fraction for mass different inlet $\mathrm{H}_{2}$ mass fraction a- 11, b-20, c- 30, and d-50

Fig. 13 Starting point of reaction zone in various inlet mass fractions of $\mathrm{H} 2$.

Fig. 14 Outlet acoustic power level at various inlet mass fractions on H2.

Fig. 15 Effects of hot co-flow inlet Reynolds number on acoustic power level, turbulence intensity, starting point of reaction zone, and net reaction rate. 
List of tables

Table $1 \quad$ Inlet components and boundary condition of the present work 


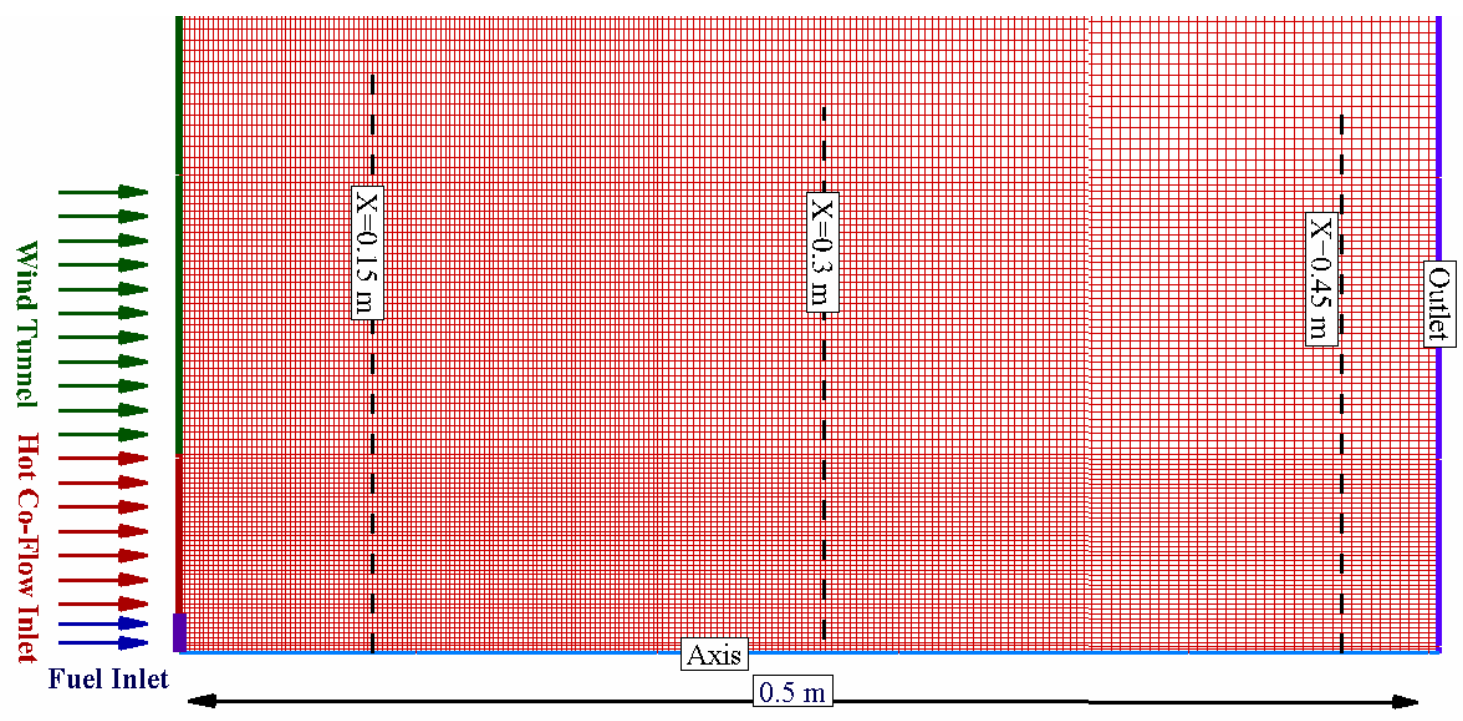

Figure 1. Schematic of present computational domain 


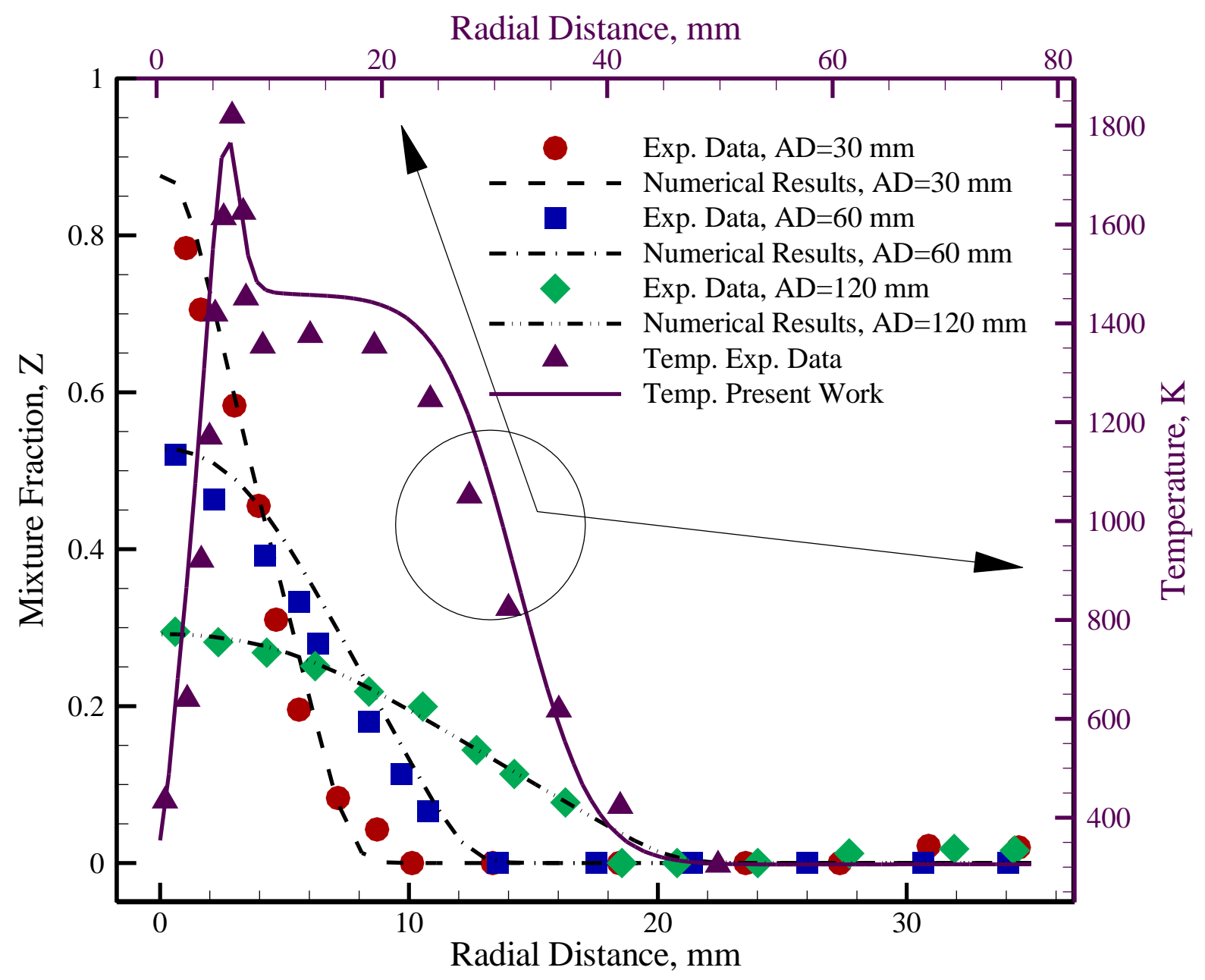

Figure 2. Validation of the current numerical method 


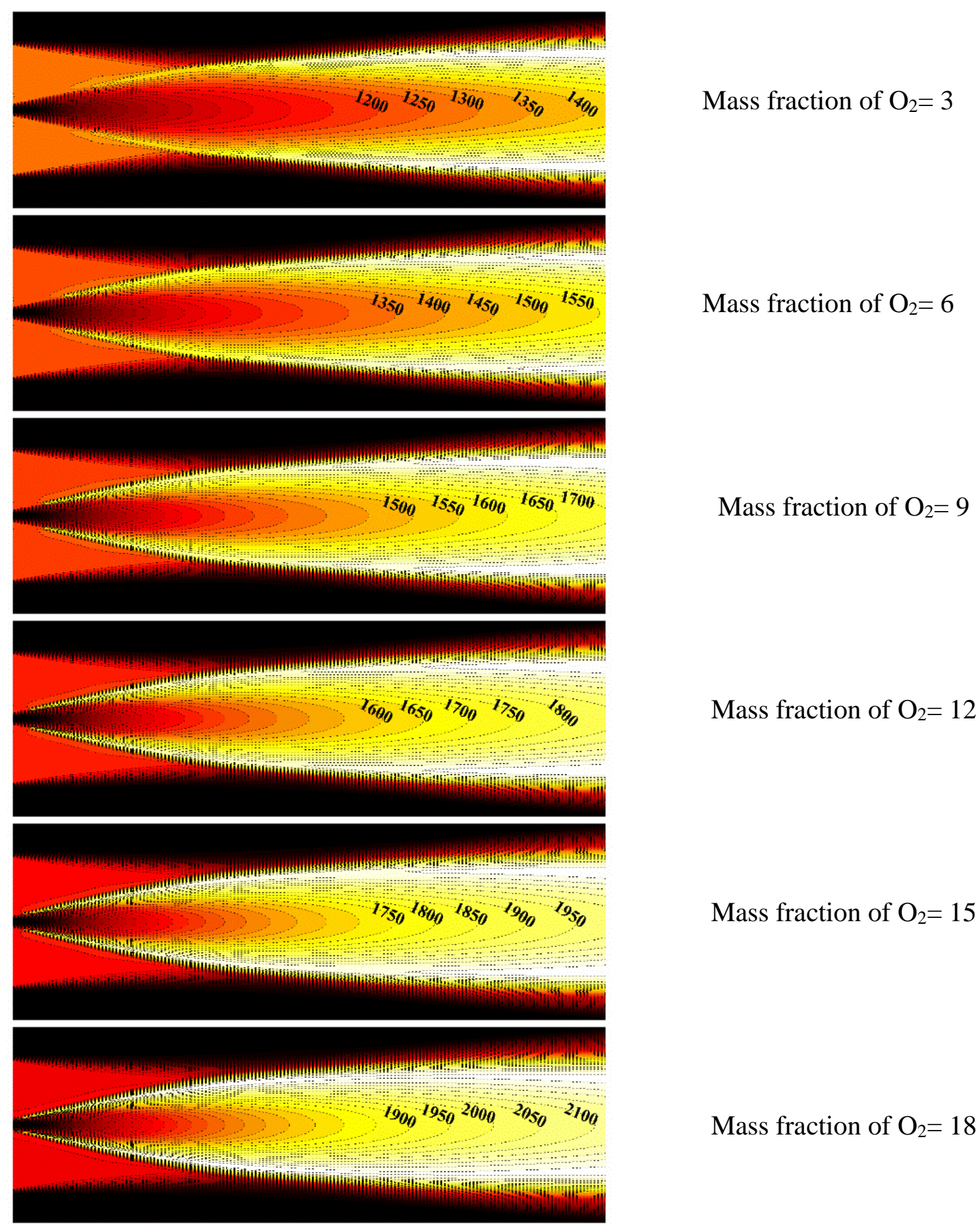

Figure 3. Contours of temperature for various inlet mass fraction of $\mathrm{O}_{2}$ 


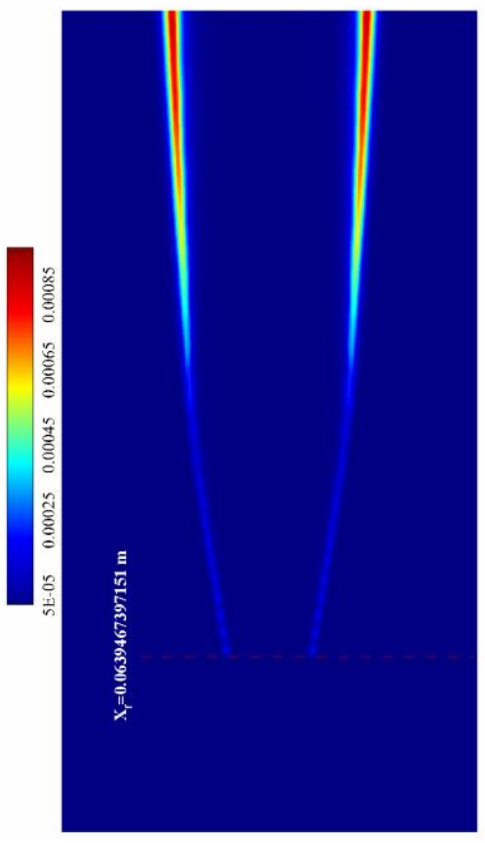

$3 \%$

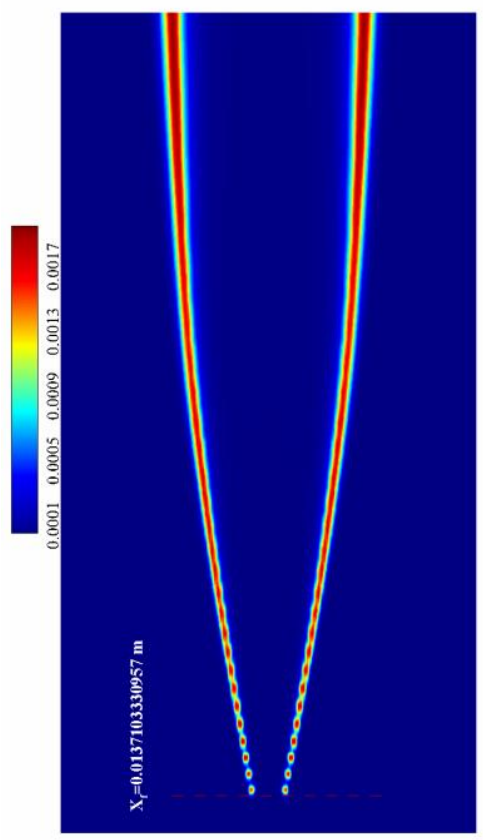

$12 \%$

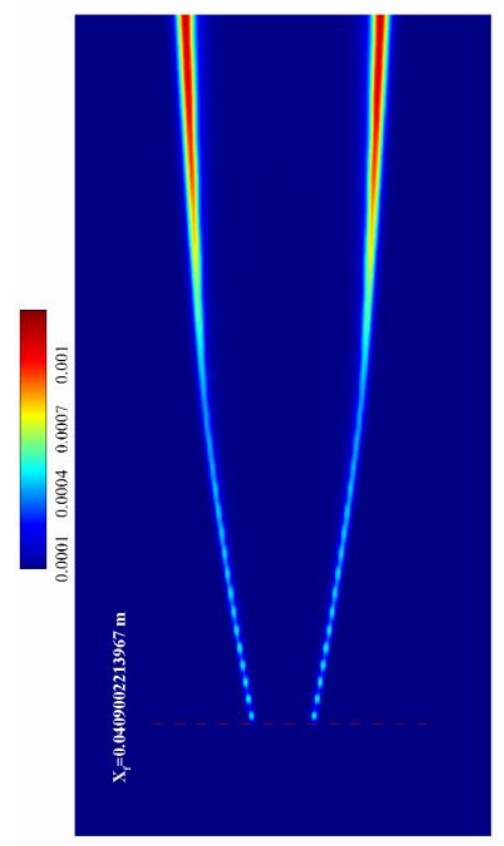

$6 \%$

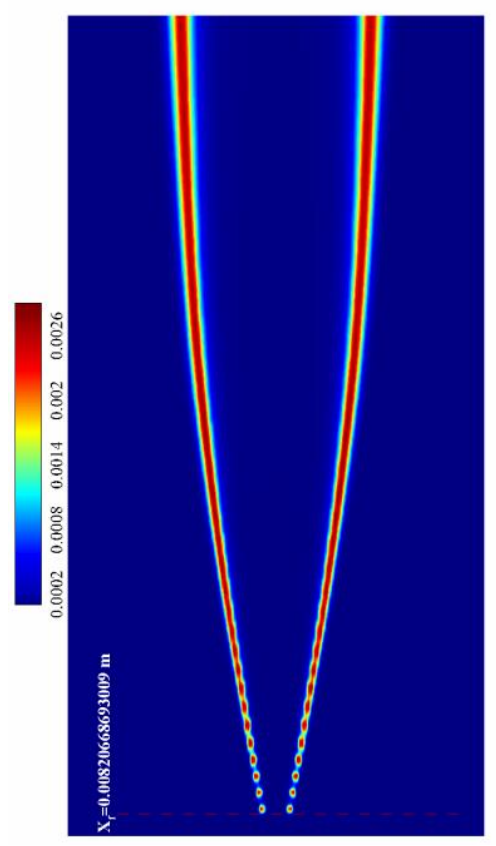

$15 \%$

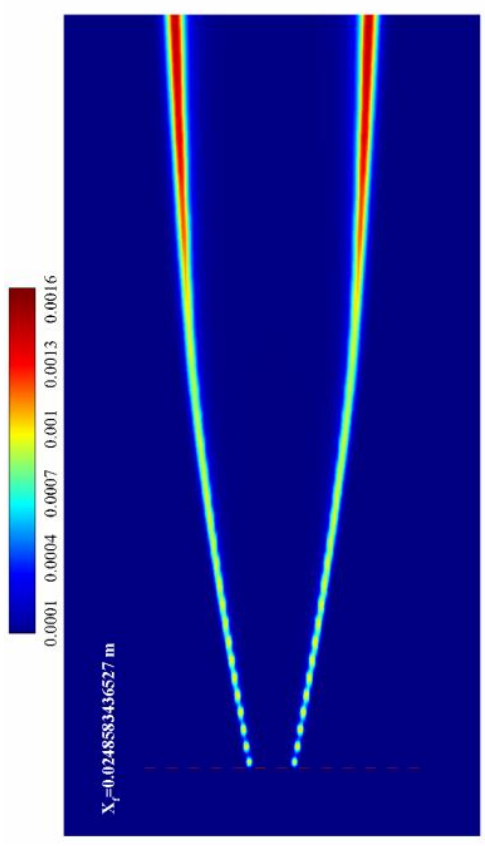

$9 \%$

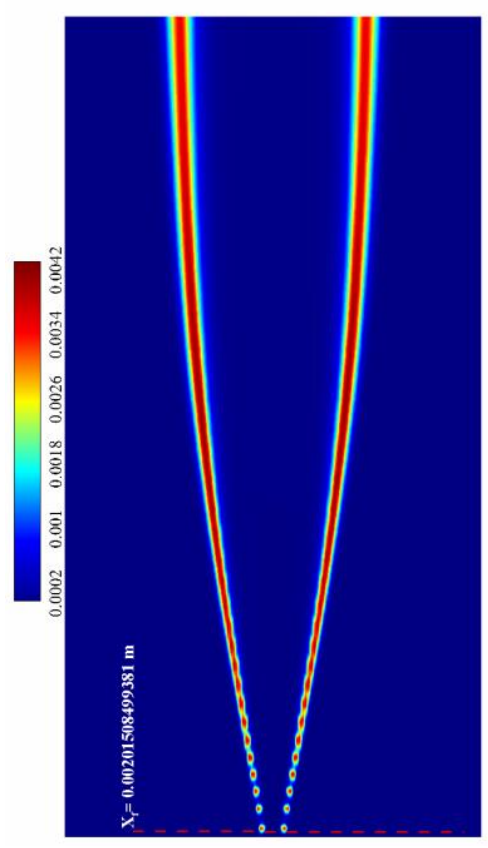

$18 \%$

Figure 4. $\mathrm{OH}$ mass fraction for various inlet mass fractions of $\mathrm{O}_{2}$ 


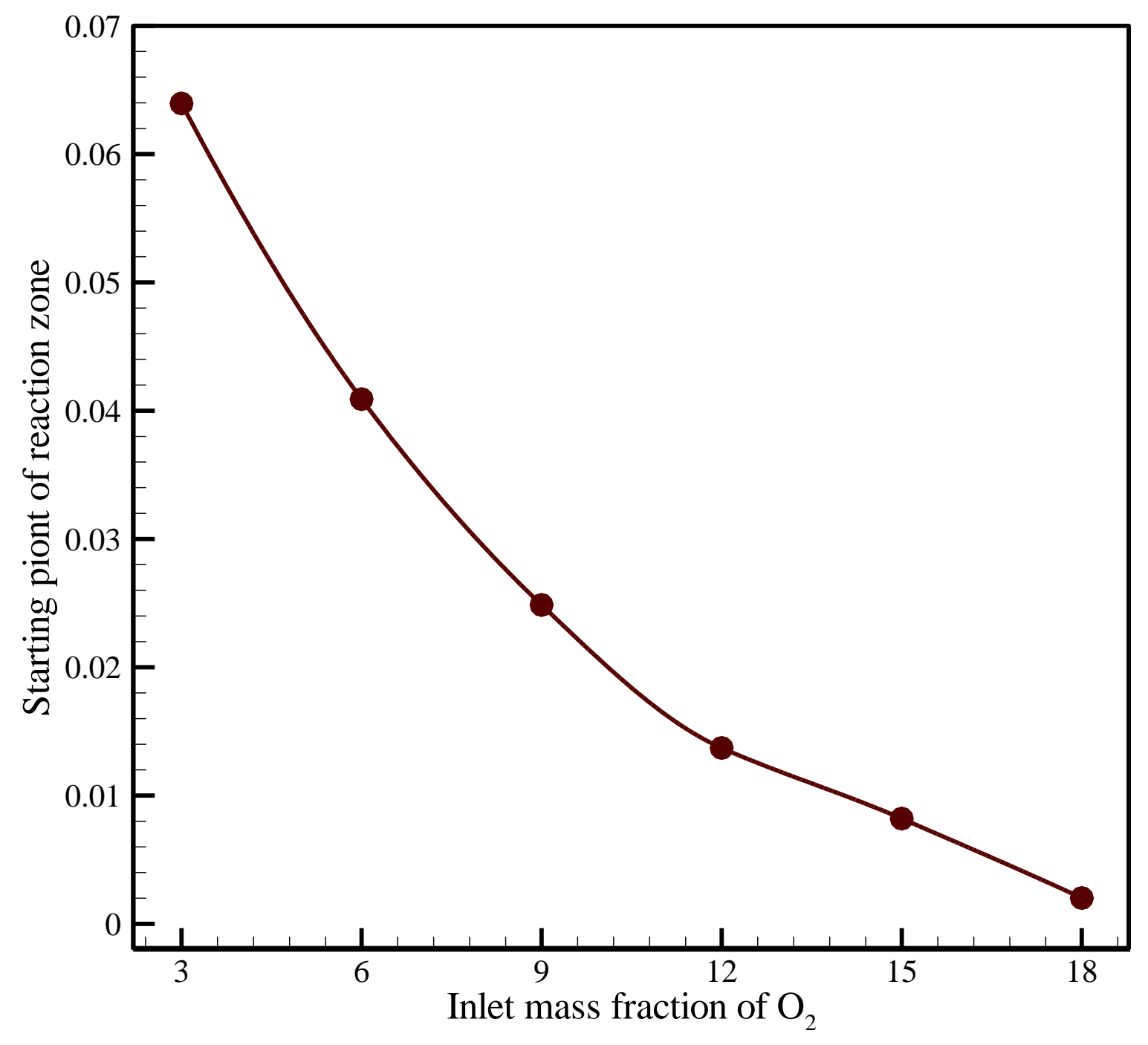

Figure 5. Effects of inlet mass fraction $\mathrm{O}_{2}$ on starting point of reaction zone 

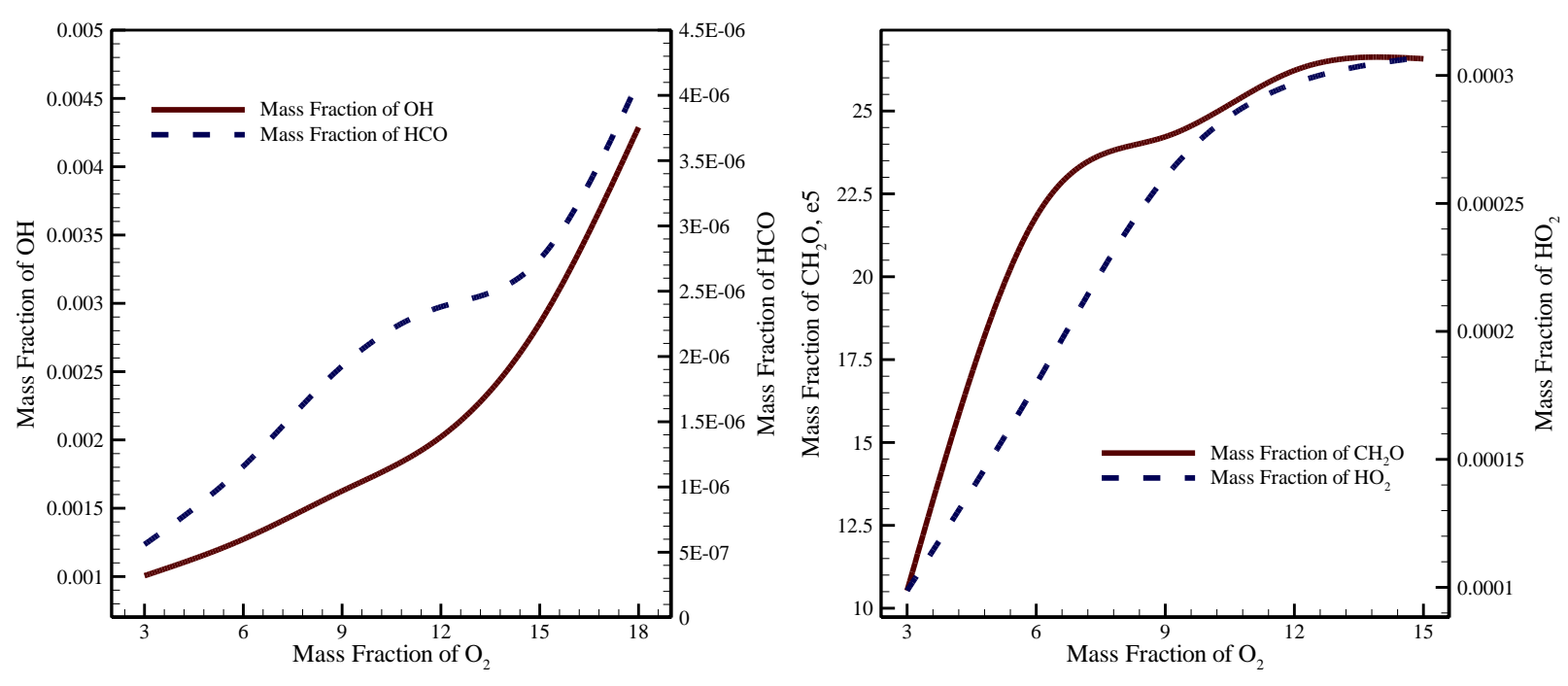

Figure 6. Effects of inlet mass fraction of $\mathrm{O}_{2}$ on mass fractions of a- $\mathrm{OH}, \mathrm{HCO}$ and b- $\mathrm{HO}_{2}$, $\mathrm{CH}_{2} \mathrm{O}$ 


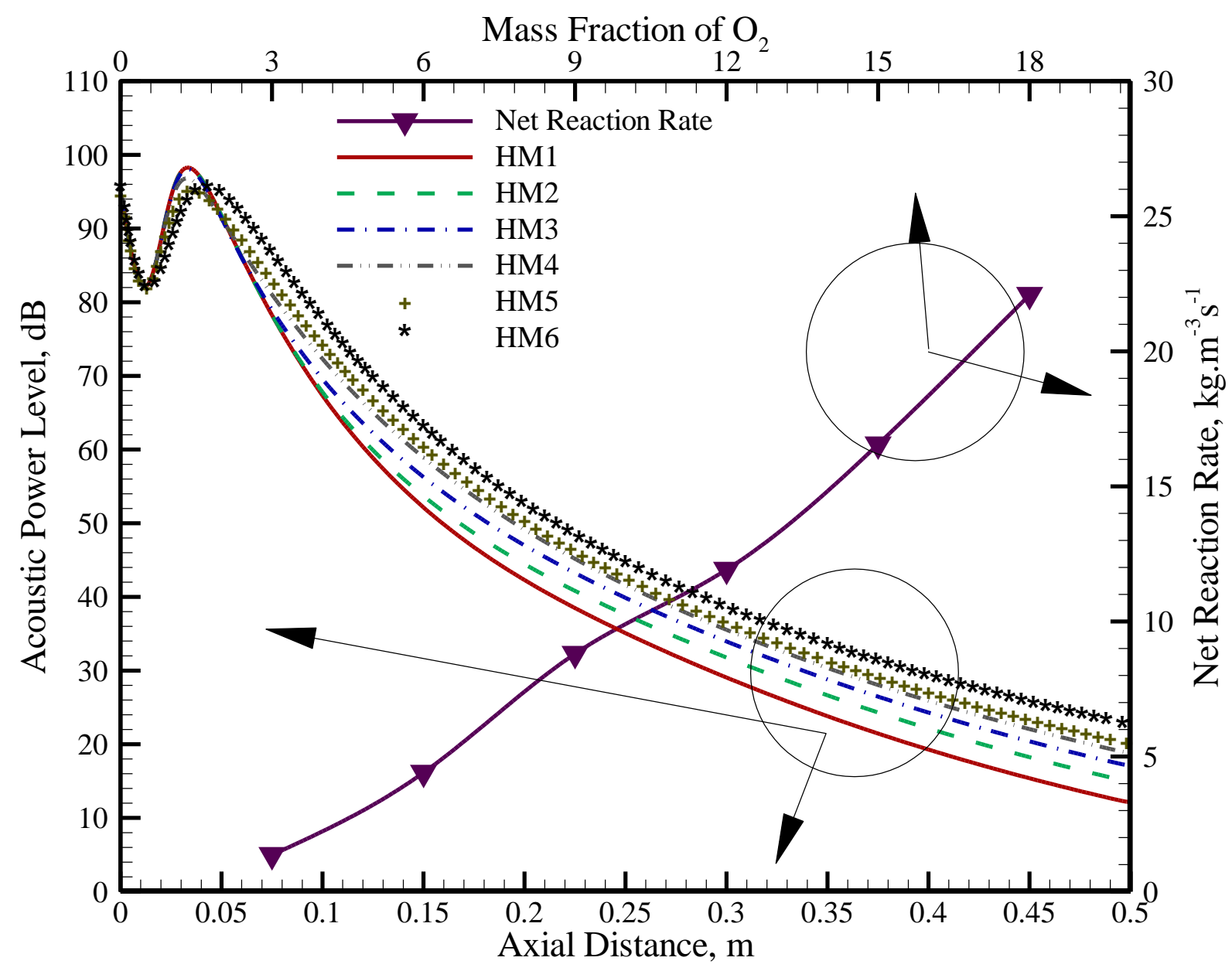

Figure 7. Effects of inlet mass fraction of $\mathrm{O}_{2}$ on acoustic power level and net reaction rate. 


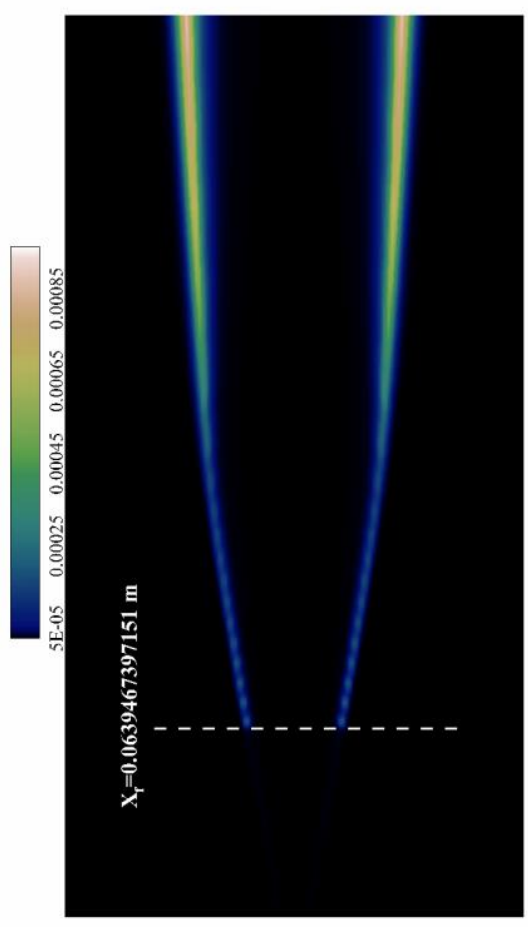

$300 \mathrm{~K}$

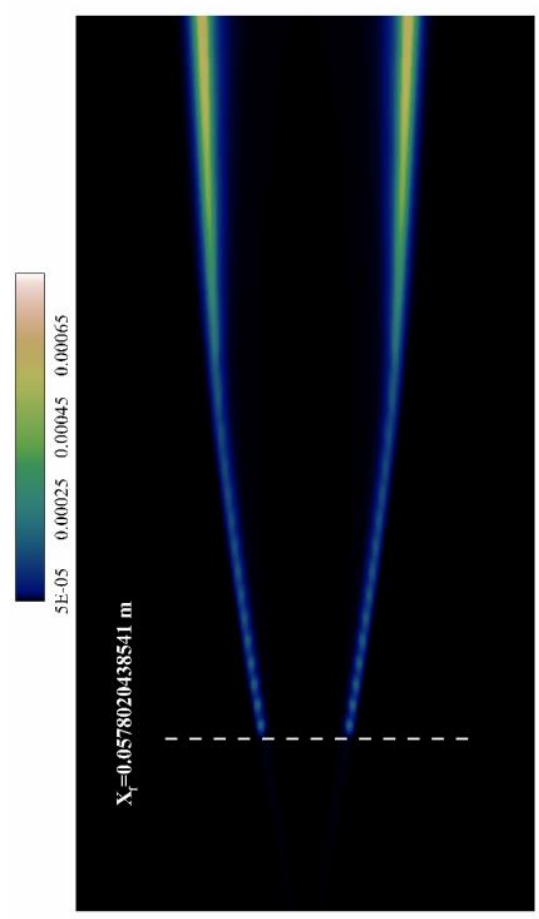

$400 \mathrm{~K}$

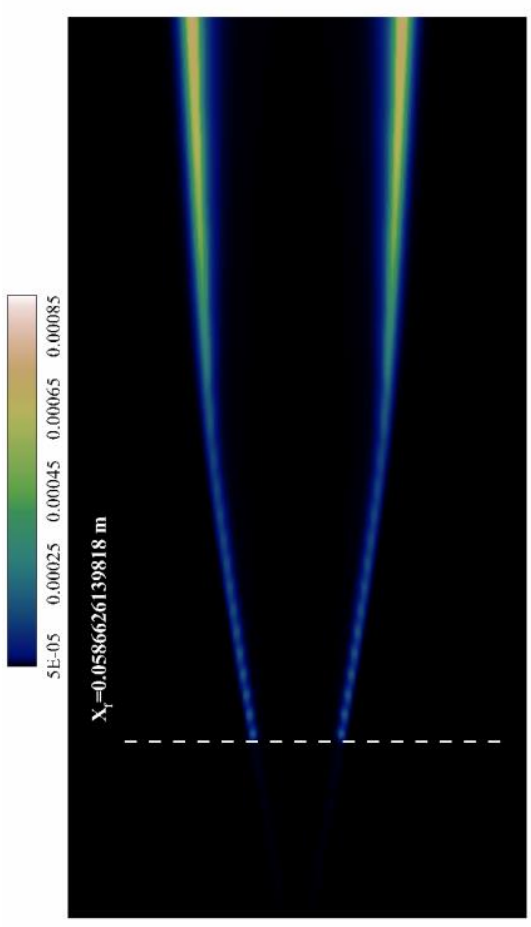

$350 \mathrm{~K}$

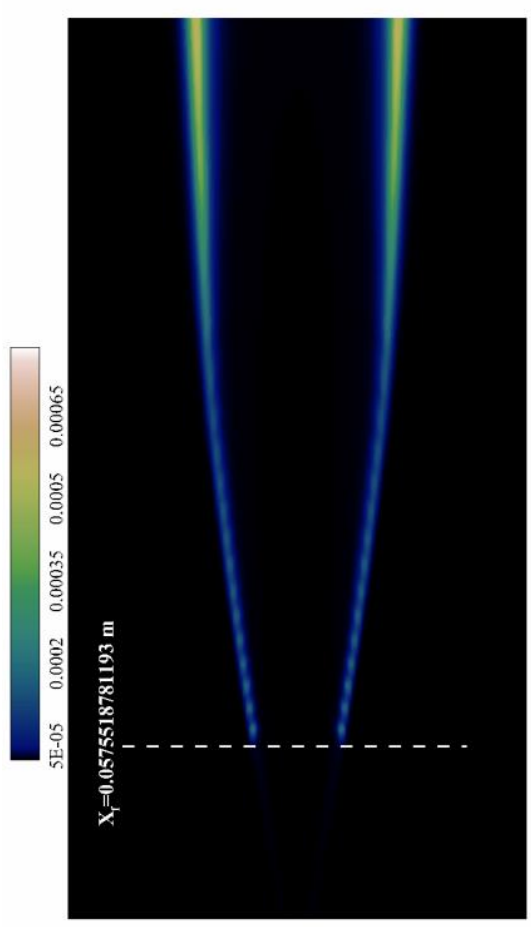

$450 \mathrm{~K}$

Figure 8. Contour of $\mathrm{OH}$ mass fraction in various inlet fuel temperatures 


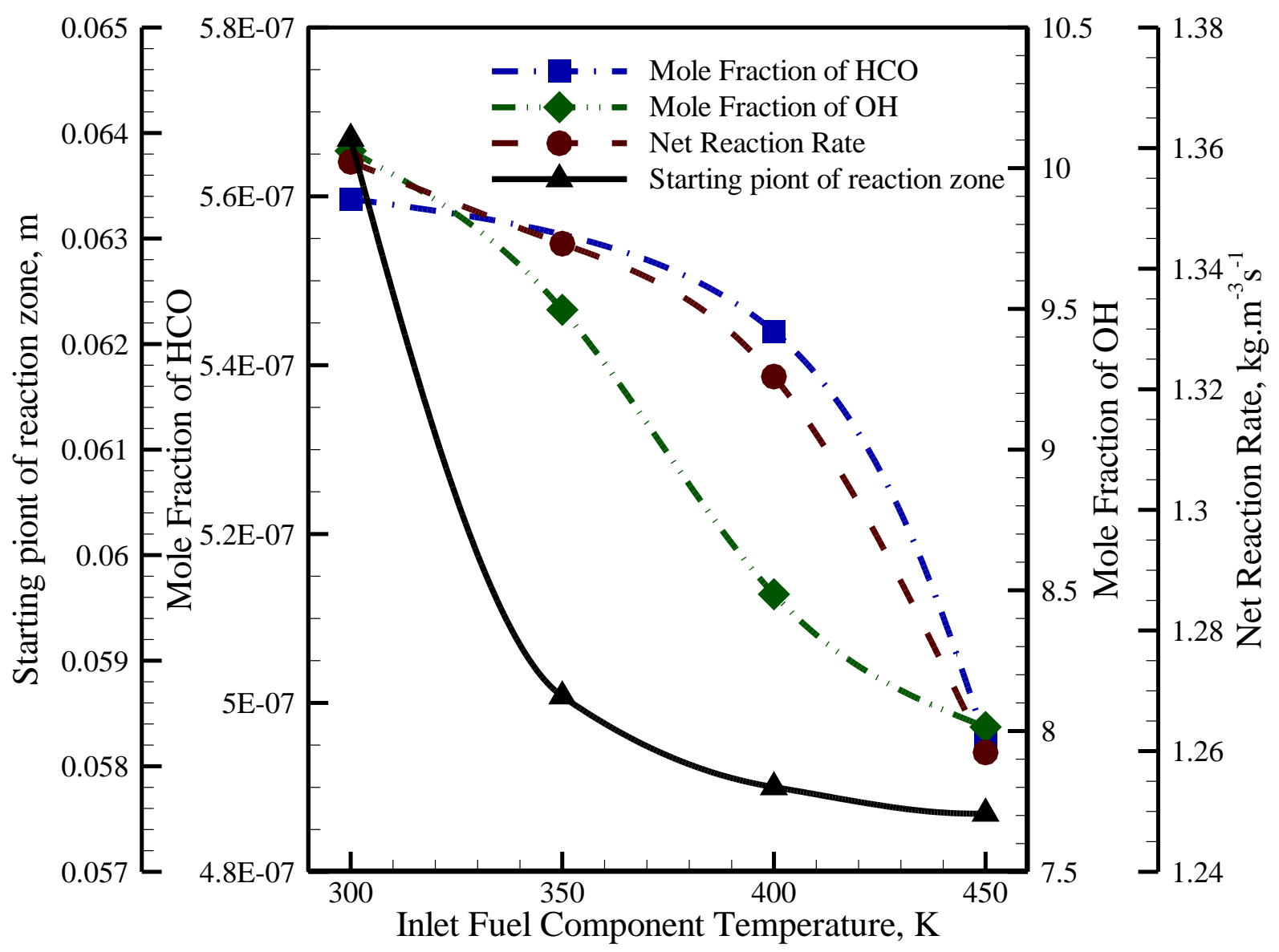

Figure 9. Effects of inlet fuel temperature on starting point of reaction zone, mole fraction of $\mathrm{HCO}, \mathrm{OH}$, and net reaction rate 


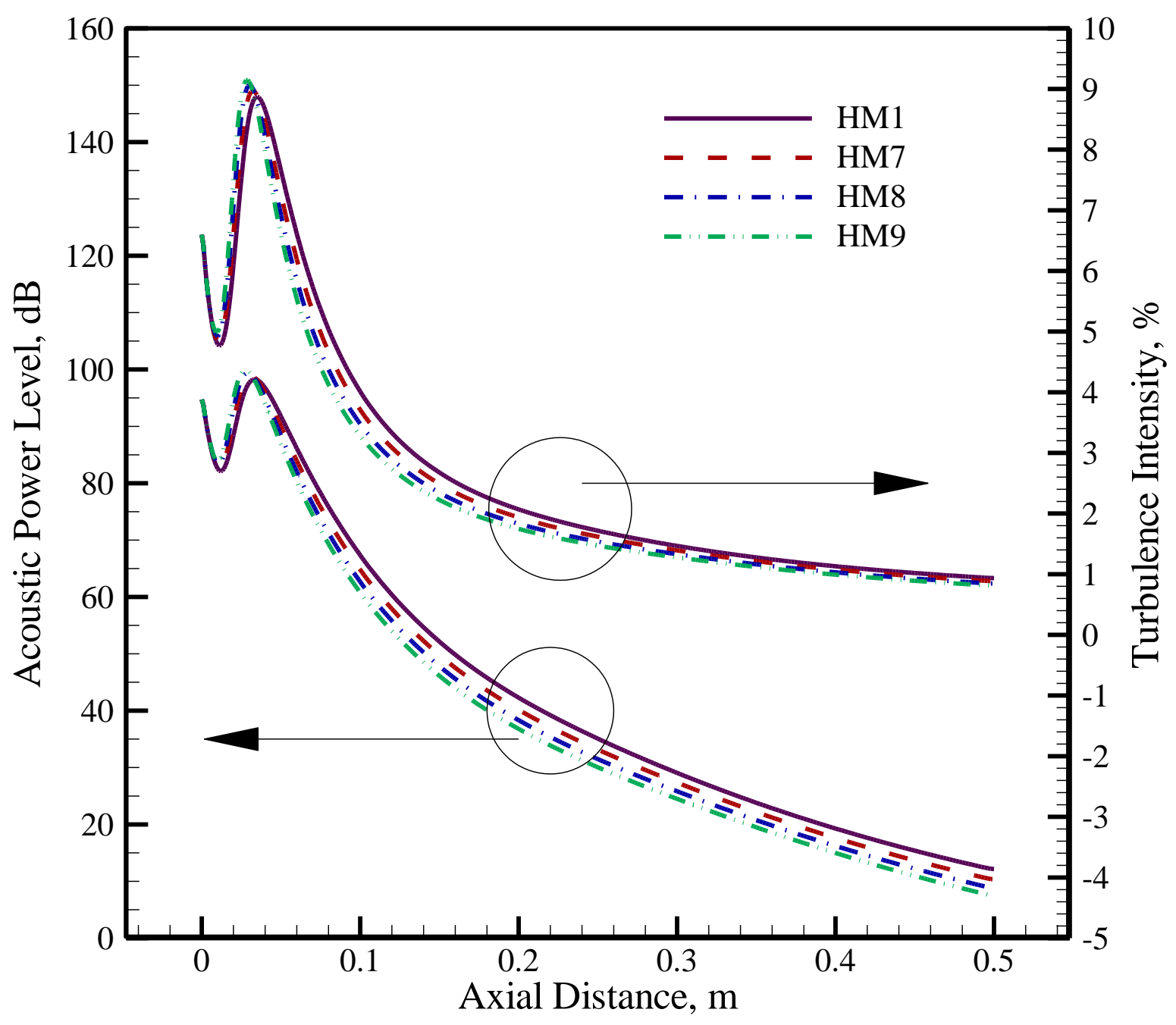

Figure 10. Effects of inlet fuel temperature on acoustic power level and turbulence intensity. 

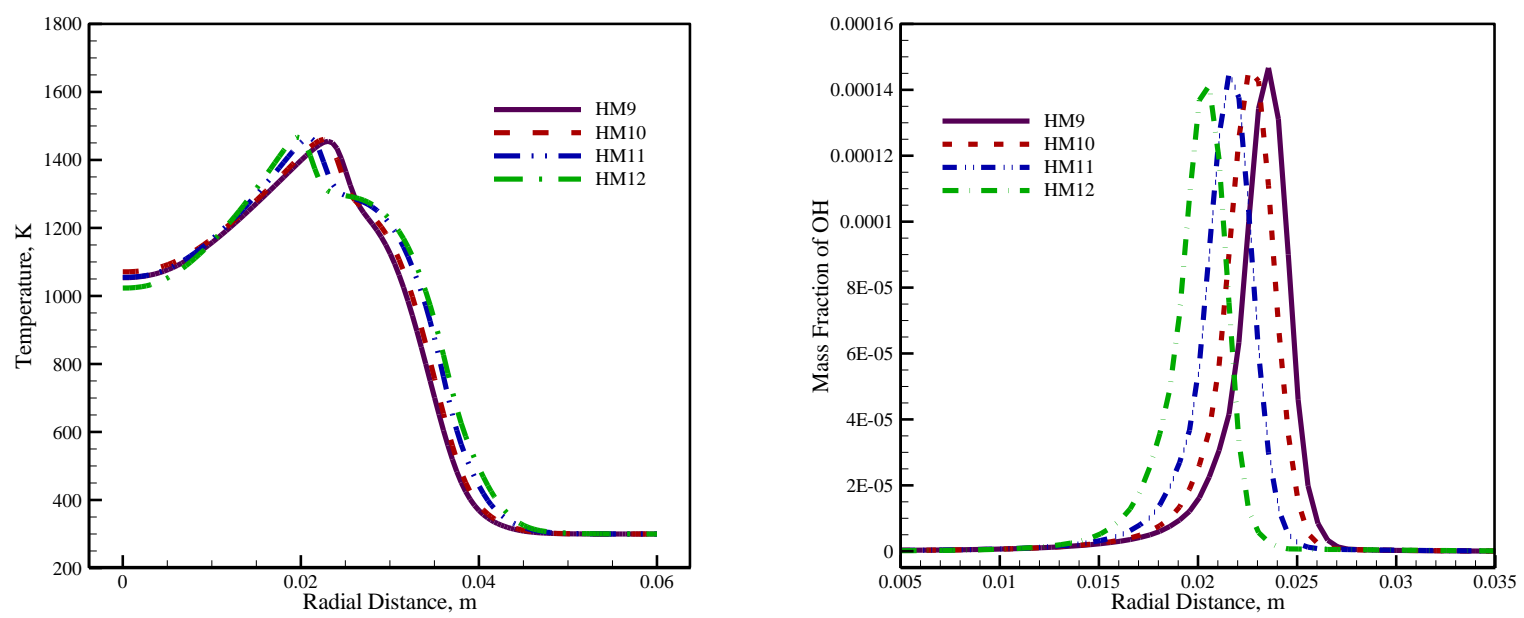

$0.15 \mathrm{~m}$
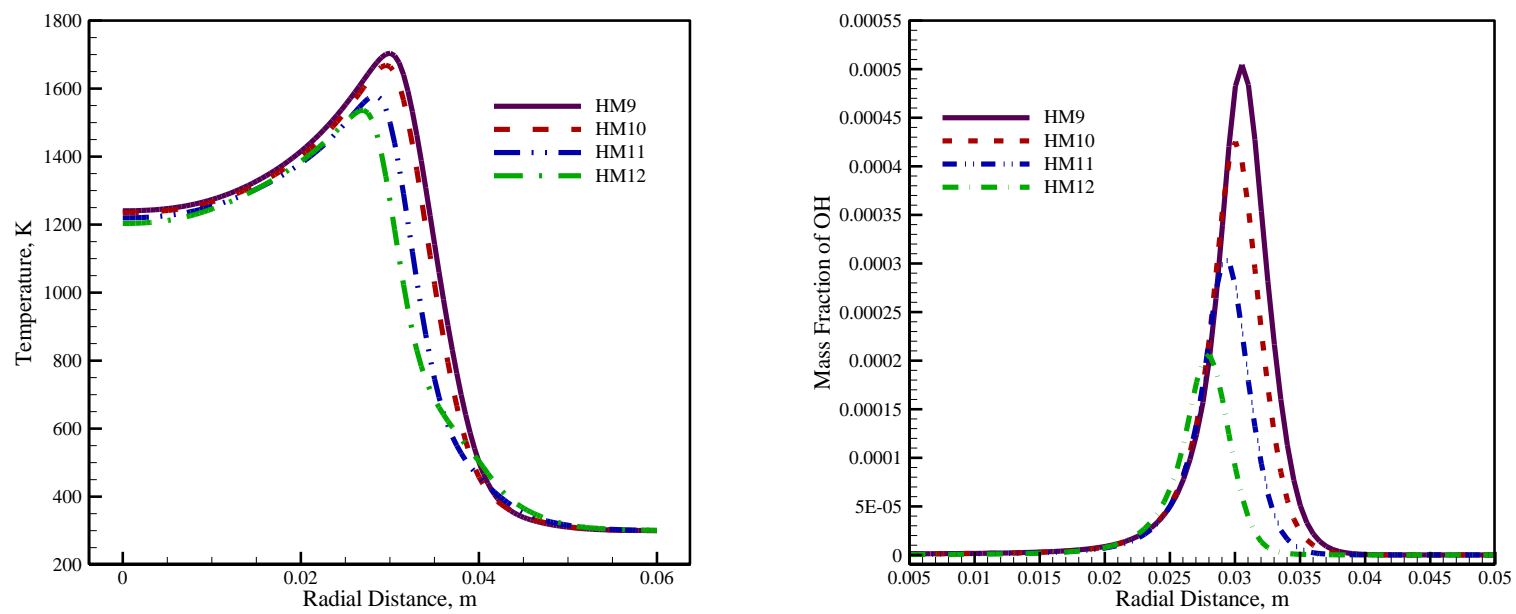

$0.3 \mathrm{~m}$
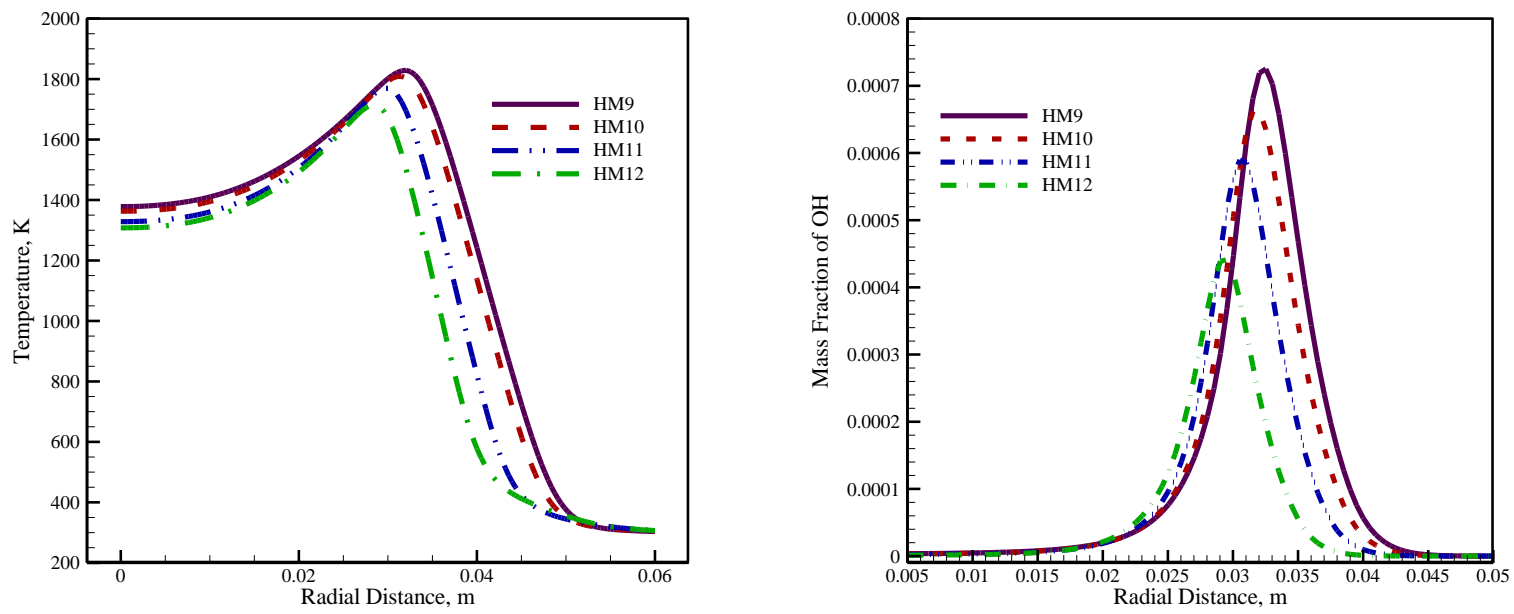

$0.45 \mathrm{~m}$

a

b

Figure 11. Effects of the inlet fuel ratio on a- temperature and b- mass fraction of $\mathrm{OH}$. 


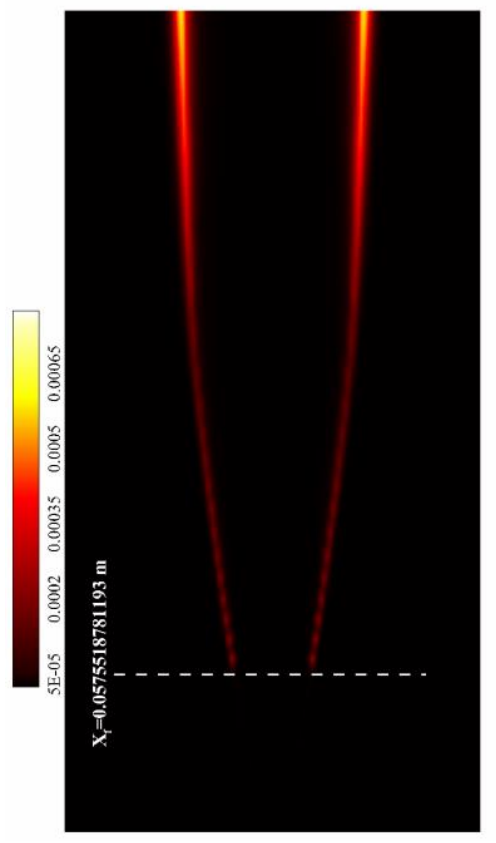

a

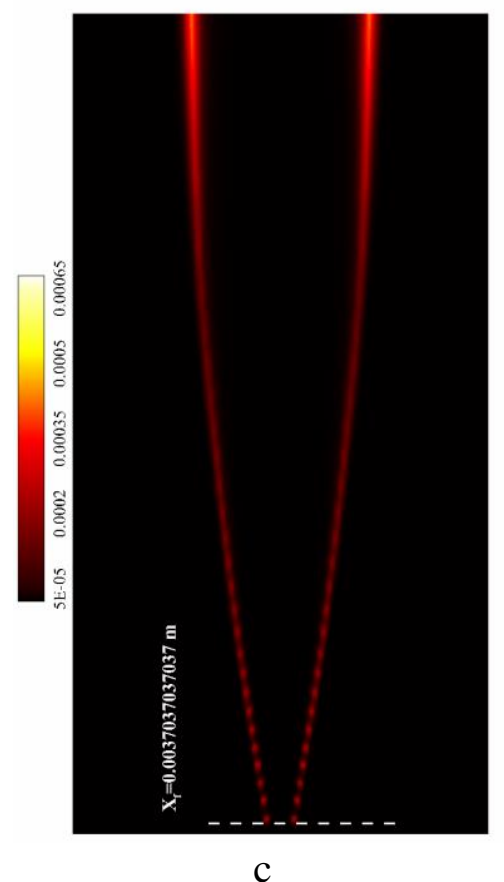

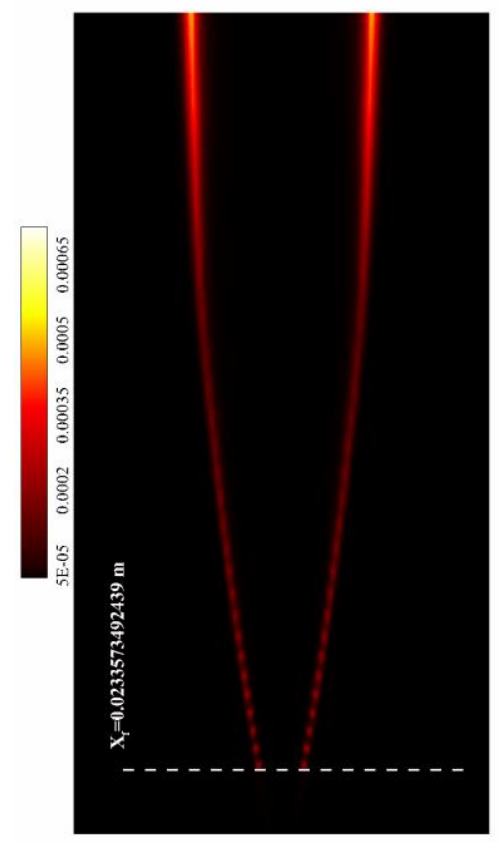

b

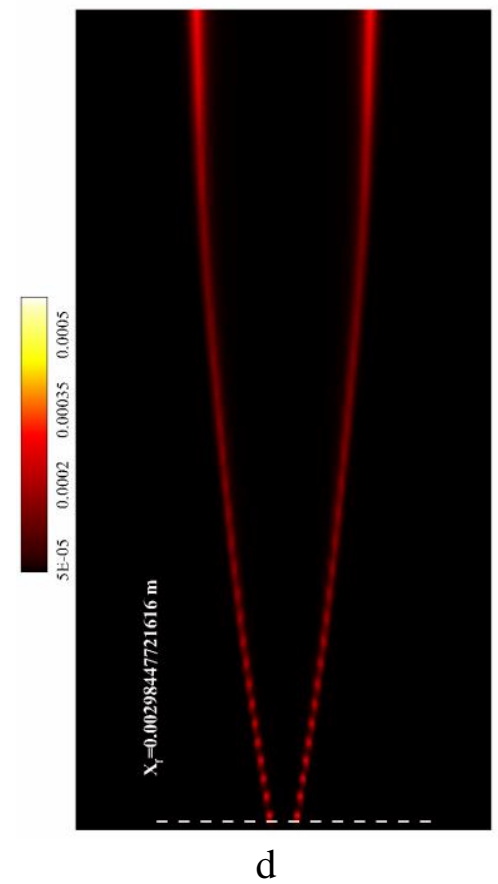

Figure 12. $\mathrm{OH}$ mass fraction for mass different inlet $\mathrm{H}_{2}$ mass fraction $\mathrm{a}-11, \mathrm{~b}-20$, c- 30, and d-50 


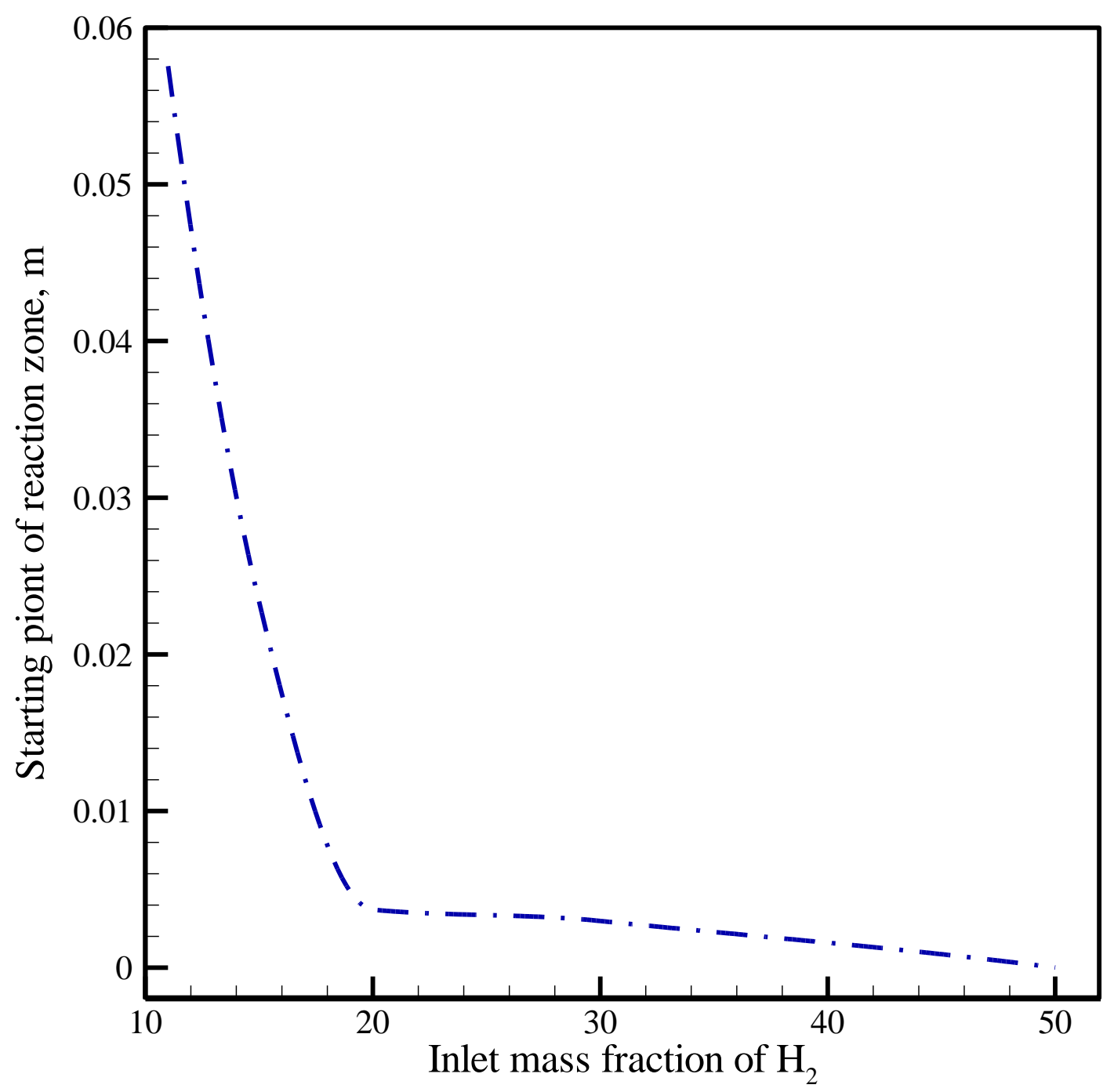

Figure 13. Starting point of reaction zone in various inlet mass fractions of $\mathrm{H} 2$. 


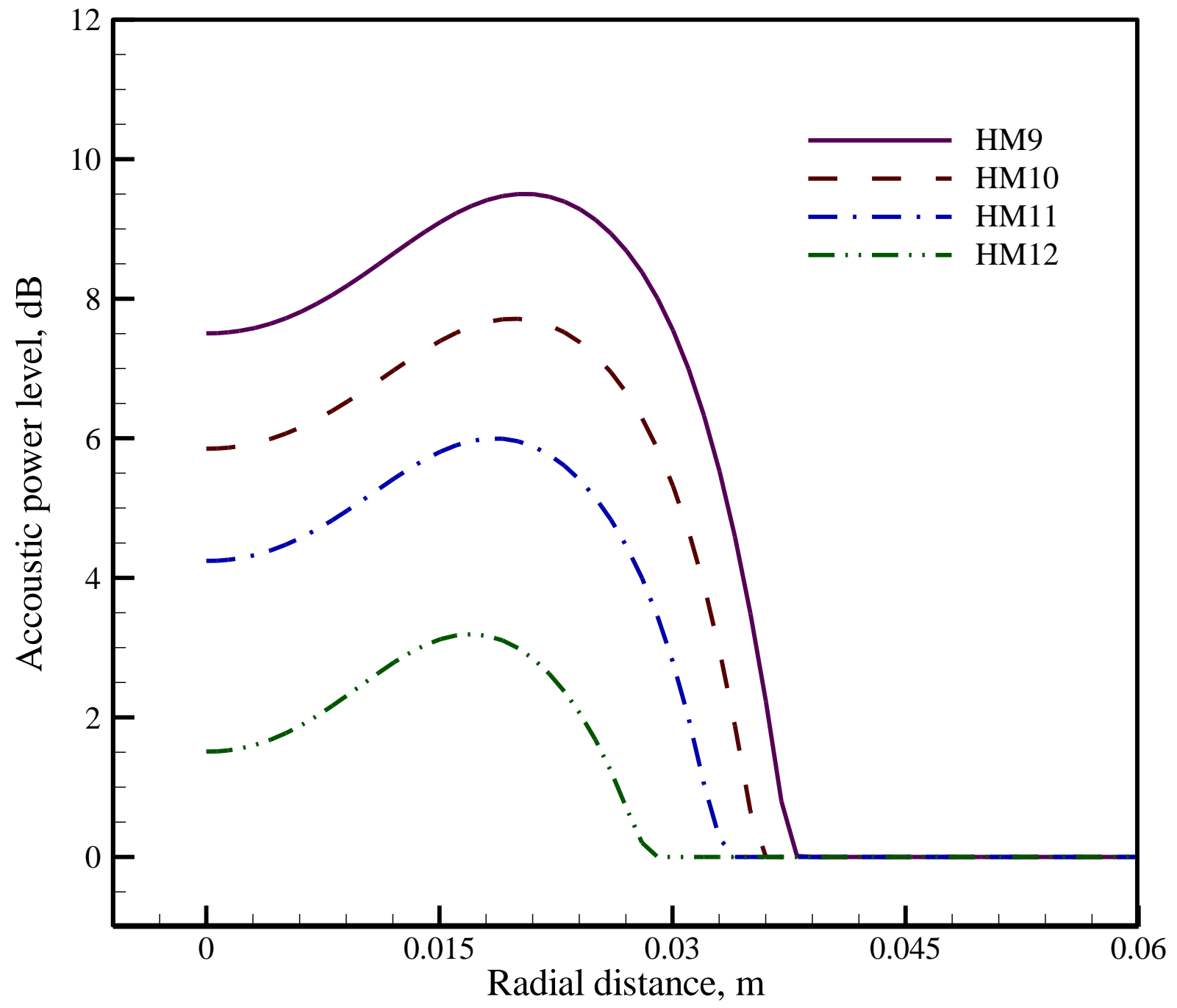

Fig. 14. Outlet acoustic power level at various inlet mass fractions on $\mathrm{H}_{2}$. 


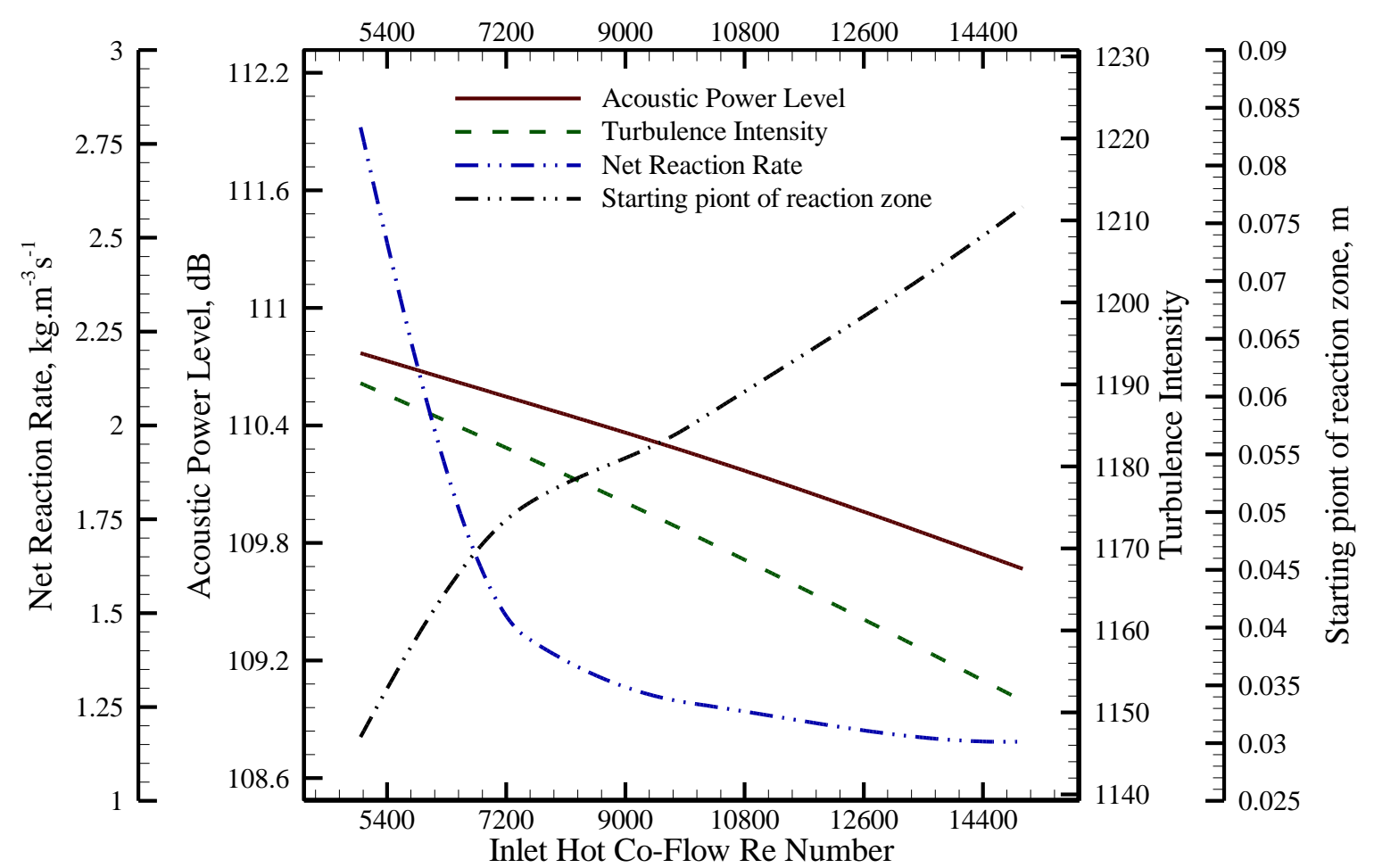

Figure 15. Effects of hot co-flow inlet Reynolds number on acoustic power level, turbulence intensity, starting point of reaction zone, and net reaction rate 
Table 1. Inlet components and boundary condition of the present work

\begin{tabular}{|c|c|c|c|c|c|c|}
\hline Case & $\begin{array}{l}\text { Mass fraction of } \\
\text { Fuel Components }\end{array}$ & $\begin{array}{l}\mathrm{U}_{\text {in }} \\
\mathrm{m} / \mathrm{s}\end{array}$ & $T_{\text {in }}, K$ & $\begin{array}{l}\text { Mass fraction of HOT } \\
\text { CO-flow components }\end{array}$ & $\mathrm{U}_{\mathrm{in}}, \mathrm{m} / \mathrm{s}$ & $\mathrm{T}_{\mathrm{in}}, \mathrm{K}$ \\
\hline HM1 & $\mathrm{H}_{2}=11.1, \mathrm{CH}_{4}=88.9$ & 70 & 300 & $\begin{array}{c}\mathrm{O}_{2}=3, \mathrm{~N}_{2}=85 \\
\mathrm{H}_{2} \mathrm{O}=6.5, \mathrm{CO}_{2}=5.5\end{array}$ & 3.2 & 1300 \\
\hline HM2 & $\mathrm{H}_{2}=11.1, \mathrm{CH}_{4}=88.9$ & 70 & 300 & $\begin{array}{c}\mathrm{O}_{2}=6, \mathrm{~N}_{2}=82, \\
\mathrm{H}_{2} \mathrm{O}=6.5, \mathrm{CO}_{2}=5.5\end{array}$ & 3.2 & 1300 \\
\hline HM3 & $\mathrm{H}_{2}=11.1, \mathrm{CH}_{4}=88.9$ & 70 & 300 & $\begin{array}{c}\mathrm{O}_{2}=9, \mathrm{~N}_{2}=79, \\
\mathrm{H}_{2} \mathrm{O}=6.5, \mathrm{CO}_{2}=5.5\end{array}$ & 3.2 & 1300 \\
\hline HM4 & $\mathrm{H}_{2}=11.1, \mathrm{CH}_{4}=88.9$ & 70 & 300 & $\begin{aligned} \mathrm{O}_{2} & =12, \mathrm{~N}_{2}=76, \\
\mathrm{H}_{2} \mathrm{O} & =6.5, \mathrm{CO}_{2}=5.5\end{aligned}$ & 3.2 & 1300 \\
\hline HM5 & $\mathrm{H}_{2}=11.1, \mathrm{CH}_{4}=88.9$ & 70 & 300 & $\begin{array}{c}\mathrm{O}_{2}=15, \mathrm{~N}_{2}=73, \\
\mathrm{H}_{2} \mathrm{O}=6.5, \mathrm{CO}_{2}=5.5\end{array}$ & 3.2 & 1300 \\
\hline HM6 & $\mathrm{H}_{2}=11.1, \mathrm{CH}_{4}=88.9$ & 70 & 300 & $\begin{array}{c}\mathrm{O}_{2}=18, \mathrm{~N}_{2}=70, \\
\mathrm{H}_{2} \mathrm{O}=6.5, \mathrm{CO}_{2}=5.5\end{array}$ & 3.2 & 1300 \\
\hline HM7 & $\mathrm{H}_{2}=11.1, \mathrm{CH}_{4}=88.9$ & 70 & 350 & $\begin{array}{c}\mathrm{O}_{2}=3, \mathrm{~N}_{2}=85, \\
\mathrm{H}_{2} \mathrm{O}=6.5, \mathrm{CO}_{2}=5.5\end{array}$ & 3.2 & 1300 \\
\hline HM8 & $\mathrm{H}_{2}=11.1, \mathrm{CH}_{4}=88.9$ & 70 & 400 & $\begin{array}{c}\mathrm{O}_{2}=3, \mathrm{~N}_{2}=85, \\
\mathrm{H}_{2} \mathrm{O}=6.5, \mathrm{CO}_{2}=5.5\end{array}$ & 3.2 & 1300 \\
\hline HM9 & $\mathrm{H}_{2}=11.1, \mathrm{CH}_{4}=88.9$ & 70 & 450 & $\begin{array}{c}\mathrm{O}_{2}=3, \mathrm{~N}_{2}=85, \\
\mathrm{H}_{2} \mathrm{O}=6.5, \mathrm{CO}_{2}=5.5\end{array}$ & 3.2 & 1300 \\
\hline HM10 & $\mathrm{H}_{2}=20, \mathrm{CH}_{4}=85$ & 70 & 450 & $\begin{array}{c}\mathrm{O}_{2}=3, \mathrm{~N}_{2}=85 \\
\mathrm{H}_{2} \mathrm{O}=6.5, \mathrm{CO}_{2}=5.5\end{array}$ & 3.2 & 1300 \\
\hline HM11 & $\mathrm{H}_{2}=30, \mathrm{CH}_{4}=70$ & 70 & 450 & $\begin{array}{c}\mathrm{O}_{2}=3, \mathrm{~N}_{2}=85 \\
\mathrm{H}_{2} \mathrm{O}=6.5, \mathrm{CO}_{2}=5.5\end{array}$ & 3.2 & 1300 \\
\hline HM12 & $\mathrm{H}_{2}=50, \mathrm{CH}_{4}=50$ & 70 & 450 & $\begin{array}{c}\mathrm{O}_{2}=3, \mathrm{~N}_{2}=85 \\
\mathrm{H}_{2} \mathrm{O}=6.5, \mathrm{CO}_{2}=5.5\end{array}$ & 3.2 & 1300 \\
\hline HM13 & $\mathrm{H}_{2}=11.1, \mathrm{CH}_{4}=88.9$ & 70 & 450 & $\begin{array}{c}\mathrm{O}_{2}=3, \mathrm{~N}_{2}=85 \\
\mathrm{H}_{2} \mathrm{O}=6.5, \mathrm{CO}_{2}=5.5\end{array}$ & 1.6 & 1300 \\
\hline HM14 & $\mathrm{H}_{2}=11.1, \mathrm{CH}_{4}=88.9$ & 70 & 450 & $\begin{array}{c}\mathrm{O}_{2}=3, \mathrm{~N}_{2}=85 \\
\mathrm{H}_{2} \mathrm{O}=6.5, \mathrm{CO}_{2}=5.5\end{array}$ & 2.4 & 1300 \\
\hline HM15 & $\mathrm{H}_{2}=11.1, \mathrm{CH}_{4}=88.9$ & 70 & 450 & $\begin{array}{c}\mathrm{O}_{2}=3, \mathrm{~N}_{2}=85, \\
\mathrm{H}_{2} \mathrm{O}=6.5, \mathrm{CO}_{2}=5.5\end{array}$ & 4.8 & 1300 \\
\hline
\end{tabular}

